\title{
AS RELAÇÕES ENTRE CHINA E AMÉRICA LATINA: IMPACTOS DE CURTAOU LONGA DURAÇÃO?
}

\author{
Matt Ferchen
}

\section{RESUMO}

O artigo foca as relações de negócios e investimentos entre China e América Latina na década de 2000. Há três interpretações principais, distintas e relacionadas, sobre esse conjunto de relações: para a primeira, a América Latina, uma região com recursos naturais abundantes, exporta produtos primários para uma China em expansão, mas carente de tais recursos. Sustentam essa interpretação aqueles, incluindo muitos representantes proeminentes do governo, que afirmam as relações econômicas entre China e América Latina serem fundamentalmente complementares, tendo um efeito positivo para ambas as partes. Em contrapartida, outros observadores têm destacado que o que é visto como complementaridade é na verdade apenas uma forma renovada de dependência latino-americana. Esses autores alegam que, apesar da rápida expansão dos negócios e investimentos trazer benefícios no curtoprazo para ambos os lados, essa natureza de relações baseada em commodities reforça os padrões disfuncionais de desenvolvimento da América Latina que muitos países da região há muito tempo renunciaram e têm tentando deixar para trás há mais de meio século. Tomando essa discussão como referência, apresenta-se, em primeiro lugar, uma visão geral das relações de comércio e investimentos entre China e América Latina, destacando o papel importante da demanda chinesa por commodities latino-americanas. Em segundo, descreve-se as diferentes interpretações sobre o que conduz essa relação comercial e quais são as suas conseqüências. Em terceiro, apresenta-se o argumento, por nós defendido, sobre como nós deveríamos entender o que tem conduzido as relações econômicas entre China e América Latina e o que está em jogo. Conclui-se explorando as implicações das nossas descobertas para a idéia de que a China oferece um modelo único de economia política doméstica e internacional.

PALAVRAS-CHAVE: negócios; investimentos; dependência; China; América Latina.

\section{INTRODUÇÃO 1}

“A mistura de ilusões, planejamentos, esperanças e medos que emergem das relações [China-América Latina] são tão poderosas em seu impacto na [América Latina] como são seus os negócios e eventos [...] no entanto, o maior impacto vindo da China virá do que ela leva a região a sonhar e o que a América Latina encontra ao acordar” (ELLIS, 2008, p. 288). Essa afirmação, um elemento de uma recente, mas

${ }^{1}$ Este artigo foi originalmente apresentado na Conferência Anual da Associação de Estudos Asiáticos na Filadélfia, EUA, em 24 de março de 2010, e novamente no primeiro Seminário Anual Sino-Brasileiro: Desenvolvimento Econômico e Segurança Internacional em Porto Alegre, Brasil, em 12 de abril de 2010. O autor gostaria de agradecer aos participantes de ambos os eventos, em particular Victor Shih e Scott Kennedy, assim como Josh Gordon, Mike Glosny, Jean-Marc Blanchard e Alicia GarcíaHerrero, por seus estimulantes comentários. crescente onda de interesse de acadêmicos, meios de comunicação, governos e empresários no crescimento econômico chinês e nas relações políticas do país com regiões do mundo em desenvolvimento como a América Latina, a África e o Sudeste Asiático, capta uma idéia importante, porém muitas vezes subvalorizada ${ }^{2}$. Especificamente, as percepções e expectativas de governos e líderes empresariais, bem como de cidadãos comuns de países na América Latina terão um

2 O foco principal deste artigo é o impacto político e econômico das relações comerciais da China com a América Latina. No entanto, muitos aspectos da economia baseada em commodities exercida pela China e seus laços de investimento com países em desenvolvimento na África, assim como com economias desenvolvidas, como da Austrália, compartilham importantes similaridades com os laços que a China mantém com a América Latina. 
papel crucial na determinação de como se desenvolverão as relações econômicas e políticas entre seus países e a China. Por seu turno, a China tem consistente e positivamente caracterizado a sua expansão do comércio e de investimentos com regiões do mundo em desenvolvimento, em particular com a América Latina, África e Sudeste Asiático, como uma parceria com benefícios mútuos ("win-win") ${ }^{3}$. Por meio de canais oficiais da diplomacia e da mídia, a China tem enfatizado que os laços mutuamente benéficos com essas regiões são um resultado lógico das relações com a China, em si um país ainda em desenvolvimento. Nesse cenário de benefício mútuo, a China alega que essas interações deveriam ser interpretadas como um resultado natural das relações "Sul-Sul"4.

Entretanto, dentro da América Latina e da África, bem como para observadores interessados de outras partes do mundo, as percepções sobre as relações de países em desenvolvimento com a China variam muito. Por um lado, está o otimismo que a China aponta como uma nova e alternativa ferramenta para promover comércio e investimentos para países em desenvolvimento. Esse otimismo é por vezes ligado à noção de que a China também serve como um modelo econômico alternativo de desenvolvimento e diplomacia internacional (RAMO, 2004; KURLANTZICK, 2007). Por outro lado, está o ceticismo e o medo sobre as intenções e influências que advirão dessa maior atuação econômica e política da China na região (HALPER, 2010). Grande parte desse controverso debate reflete-se no rápido crescimento das discussões na academia e na mídia a respeito das idéias sobre um provável "Consenso de Beijing” ou "Modelo Chinês" de desenvolvimento ${ }^{5}$. Uma das principais questões levantadas é sobre se o atual ritmo acelerado de expansão dos negócios e investimentos da China com o mundo em

\footnotetext{
3 Para mais informações sobre a diplomacia “win-win” da China para o Sudeste Asiático ver Michael A. Glosny (2006).

4 Para mais informações sobre as relações entre a China e a América Latina como "Sul-Sul”, ver Monica Hirst (2008) e Jiang Shixue (2005).

5 Para estudos recentes sobre esses conceitos, ver Scott Kennedy (2010), Barry Naughton (2010), Suisheng Zhao (2010) e Matt Ferchen (no prelo).
}

desenvolvimento é uma relação de igualdade e de natureza sustentável ou se é similar às relações históricas entre países desenvolvidos e em desenvolvimento.

Para avaliar essas percepções concorrentes otimista versus pessimista -, este artigo centrase nas relações de negócios e investimentos entre China e América Latina na última década. Com foco especial nos laços entre China e América Latina, essas percepções apresentam-se em dois conjuntos distintos, embora relacionados, de interpretações de um consenso geral sobre um conjunto de fatos: América Latina, uma região com recursos naturais abundantes, que exporta produtos primários para uma China em expansão, mas carente de tais recursos. Ao lado desse debate emergente estão aqueles, incluindo muitos representantes proeminentes do governo, que afirmam que as relações econômicas entre China e América Latina são fundamentalmente complementares, tendo, portanto, um efeito positivo para ambas as partes. Em contrapartida, outros observadores têm destacado que o que vêem como complementaridade é na verdade apenas uma forma renovada de dependência latino-americana. Eles alegam que, apesar da rápida expansão dos negócios e investimentos trazer benefícios no curto-prazo para ambos os lados, essa natureza de relações baseada em commodities reforça os padrões disfuncionais de desenvolvimento da América Latina que muitos países da região há muito tempo renunciaram e têm tentado deixar para trás há mais de meio século.

Cada versão dessas narrativas concorrentes pode representar, mesmo que às vezes de maneira contraditória, elementos importantes sobre as relações de investimento e comércio da China com a América Latina. Entretanto, faltando em ambas as perspectivas de "complementaridade" e "dependência” está um foco específico nas forças motoras que estão por trás da expansão do comércio e dos investimentos na América Latina (para não mencionar também a África e a Austrália, por exemplo). Em particular, especialistas da expansão das relações econômicas entre China e América Latina freqüentemente deixam de analisar as forças econômicas e as políticas governamentais dentro da China que têm direcionado a demanda chinesa por commodities específicas como minério de 
ferro, cobre ou soja. Como resultado, vertentes teóricas de complementaridade ou de dependência também ficam aquém das expectativas por não proverem uma maior compreensão mais completa das relacionadas conseqüências econômicas e políticas da expansão das relações econômicas entre China e América Latina. Este artigo, por-tanto, demonstrará como aparentemente o senso comum de que a América Latina simplesmente possui os recursos naturais "necessários" ao rápido desenvolvimento econômico da China atrapalha a compreensão de detalhes importantes sobre o momento e as razões para a rápida elevação nas exportações de commodities dos países latino-americanos ricos em recursos naturais para a China no início dos anos 2000.

Suposições de que a demanda chinesa por matéria-prima da América Latina e de outros lugares é simplesmente uma função natural do rápido e constante desenvolvimento econômico da China nos últimos mais de 30 anos são incompletas, na melhor das hipóteses, e enganosas, na pior. Esse tipo de compreensão não leva em conta importantes mudanças na economia política doméstica da China no início dos anos 2000, as quais foram acompanhadas por um aumento abrupto dos laços de comércio e investimentos com o mundo em desenvolvimento e outros países grandes produtores de commodi-ties, como a Austrália. De maneira mais específica, iniciando por volta de 2002 e 2003, e revertendo tendências que estavam em vigor desde o começo das reformas no final da década de 1970, a economia chinesa entrou em um período de acelerado uso de capital intensivo para o cresci-mento de sua indústria de base. Isso, na verdade, alavancou a demanda por matérias-primas, incluindo uma variedade de minerais, mentais e fontes de energia, para suprir sua indústria de base. Para satisfazer essa demanda a China tem crescentemente se voltado para os países ricos em commodities da América Latina, África e outros lugares. Assim, a demanda chinesa por matérias-primas - que exigiu em si a manutenção de laços estreitos com países-chave, ricos em commodities, na trajetória de desenvolvimento da indústria de base da última década -, funciona como pilar de sustentação de seu relacionamento com muitos dos maiores e mais importantes países latino-americanos e outros grandes produtores de produtos primários. O rápido aumento das importações de matérias-primas feitas pela China de países da América Latina, África e outros lugares é um dos principais indicadores de um aumento súbito das commodities, que tem apresentado elevados volumes e preços de certos minerais, de energia e de produtos agrícolas. Esse rápido incremento de preços tem sido a base econômica, e também política, que sustenta os renovados laços da China com muitas nações em desenvolvimento não só da América Latina, mas também de outras partes do globo.

Essa tendência de intensa demanda da China por commodities, muitas das quais foram direcionadas para abastecer o capital intensivo do país, crescimento e desenvolvimento da indústria de base, tem somente sido exposta pela resposta da China à crise financeira global. Em particular, o pacote de estímulos e as políticas de relaxamento da concessão de crédito da China estimularam investimentos ainda maiores em infraestrutura, desenvolvimento da propriedade e indústria de base. Mesmo antes da crise financeira havia preocupações dentro e fora da China de que seu afastamento de uma trajetória leve para uma pesada trajetória de desenvolvimento estava criando potenciais resultados desestabilizadores, especialmente no campo de segurança energética. Essas advertências têm somente se intensificado à luz da resposta chinesa à crise financeira.

No entanto, essa mudança no padrão doméstico de crescimento da China e seu papel fundamental em conduzir o crescimento súbito das commodities têm estado visivelmente ausente na academia, na mídia e em análises governamentais sobre a expansão das relações da China com regiões do mundo com abundantes recursos naturais. $\mathrm{O}$ fracasso em identificar essa origem da expansão da demanda chinesa por recursos naturais da América Latina e de outros lugares tem também impedido uma compreensão mais acurada sobre as consequências potenciais para o longo-prazo da saúde e da estabilidade dos laços de investi-mento e comércio, sem mencionar o político, da China com parceiros ricos em recursos. O laço político, por sua vez, tem facilitado um descompasso entre as altas expectativas e o aumento dessas sobre o papel que a China vai continuar desempenhando na promoção do crescimento da América Latina e 
dos muitos desafios que a China enfrenta para manter seu ritmo acelerado de desenvolvimento. O último resultado é uma subavaliação de como o recente e súbito aumento das relações entre China e América Latina está sustentado em bases estreitas e fundamentos econômicos mais frágeis do que o comumente entendido.

A estrutura deste artigo é a seguinte. Primeiro, apresentarei uma visão geral das relações de comércio e investimentos entre China e América Latina, destacando o papel importante da demanda chinesa por commodities latino-americanas. Segundo, descreverei e avaliarei as diferentes interpretações sobre o que conduz esse relacionamento comercial e quais são as conseqüências para a relação. Na seqüência, apresentarei então o meu argumento sobre como nós deveríamos entender o que tem conduzido as relações econômicas entre China e América Latina e o que está em jogo segundo minha compreensão. $\mathrm{Na}$ conclusão exploro as implicações das minhas descobertas segundo a idéia de que a China oferece um modelo único de economia política doméstica e internacional.

\section{II.COMÉRCIO E INVESTIMENTOS ENTRE CHINA E AMÉRICA LATINA: OS FATOS ESTILIZADOS}

Antes de explorar as explicações mais comuns sobre a expansão dos laços econômicos entre China e América Latina e as interpretações concorrentes sobre as conseqüências desses laços, apresento primeiramente um retrato básico das relações de comércio e de investimento entre a China e a América Latina. A força motriz por trás dos laços econômicos em expansão entre a China e a América Latina é a demanda chinesa por minérios, energia e commodities agrícolas. Em troca de suas exportações de matérias primas, a América Latina importa uma variedade de bens chineses manufaturados (ver o Gráfico 1). Além disso, o rápido aumento dos laços comerciais, em escala e velocidade (e, em menor extensão, do investimento), entre a América Latina e a China é de origem relativamente recente, decolando apenas nos anos mais recentes da década de 2000 (ver o Gráfico 2). Entender a natureza baseada em comodities da relação econômica e o momento inicial são ambos cruciais para qualquer avaliação geral da direção e saúde, em longo termo, dos laços econômicos e políticos entre a China e a América Latina.

GRÁFICO 1 - COMÉRCIO DE MATÉRIAS-PRIMAS E MANUFATURAS ENTRE CHINAEAMÉRICA LATINA, 2006

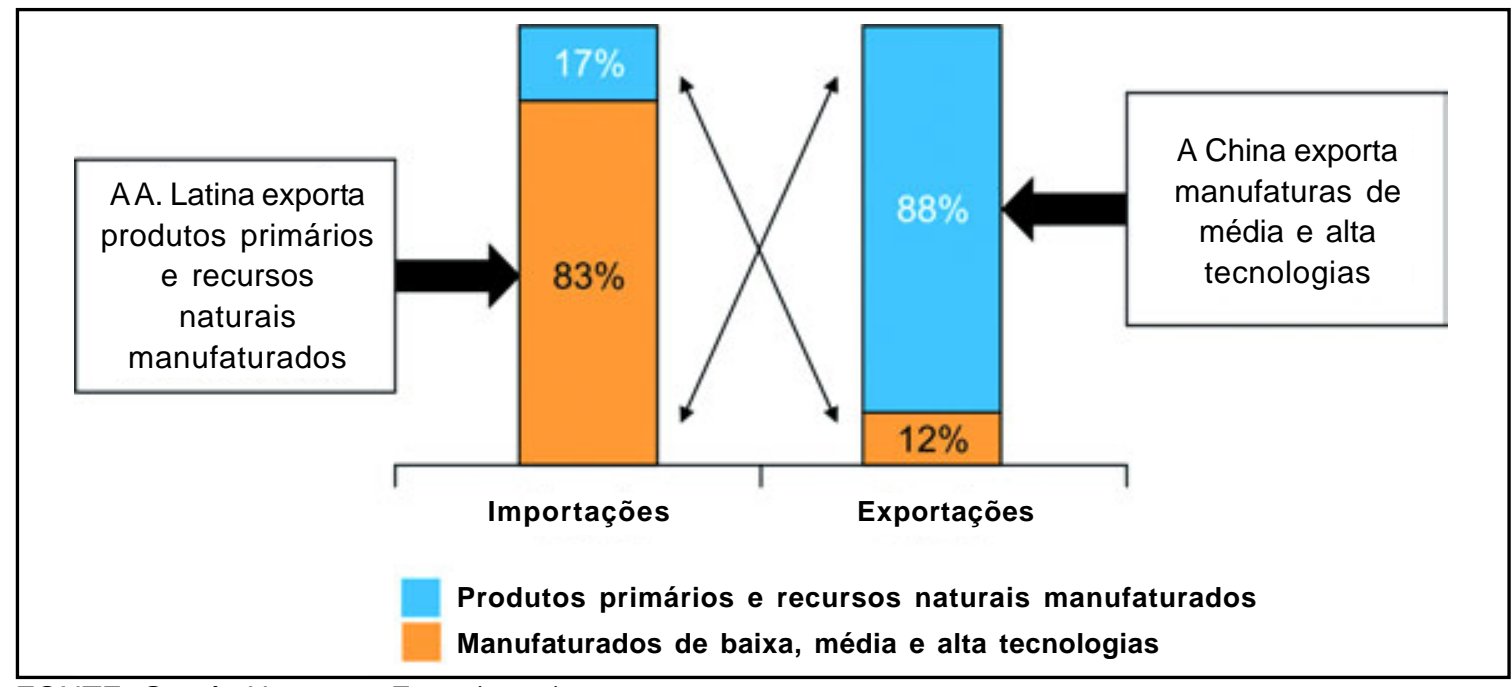

FONTE: García-Herrero e Fung (2008).

Apesar da crescente atenção acadêmica prestada ao investimento estrangeiro direto (FDI, na sigla em inglês) chinês na América Latina e outros países, a expansão dos fluxos de comércio entre China e América Latina têm sido de magnitude e importância muito maiores que o FDI chinês na região. Certamente, enquanto a China recuperouse rapidamente da crise financeira, ela também aumentou o investimento direto, não-portfólio, na América Latina, especialmente no Brasil 
(GRAHAM, 2010; POMFRET, 2010). Entretanto, mesmo esse maior investimento tem sido principalmente em matérias primas como energia e minérios. Assim, enquanto líderes governamentais e de negócios na América Latina esperam ver o comércio e o investimento com a China expandir-se além dos interesses chineses em matérias primas, as commodities continuam a representar o fundamento da relação entre eles.

\section{GRÁFICO 2 -AUMENTO RECENTE DAS EXPORTAÇÕES LATINO-AMERICANAS PARAACHINA}

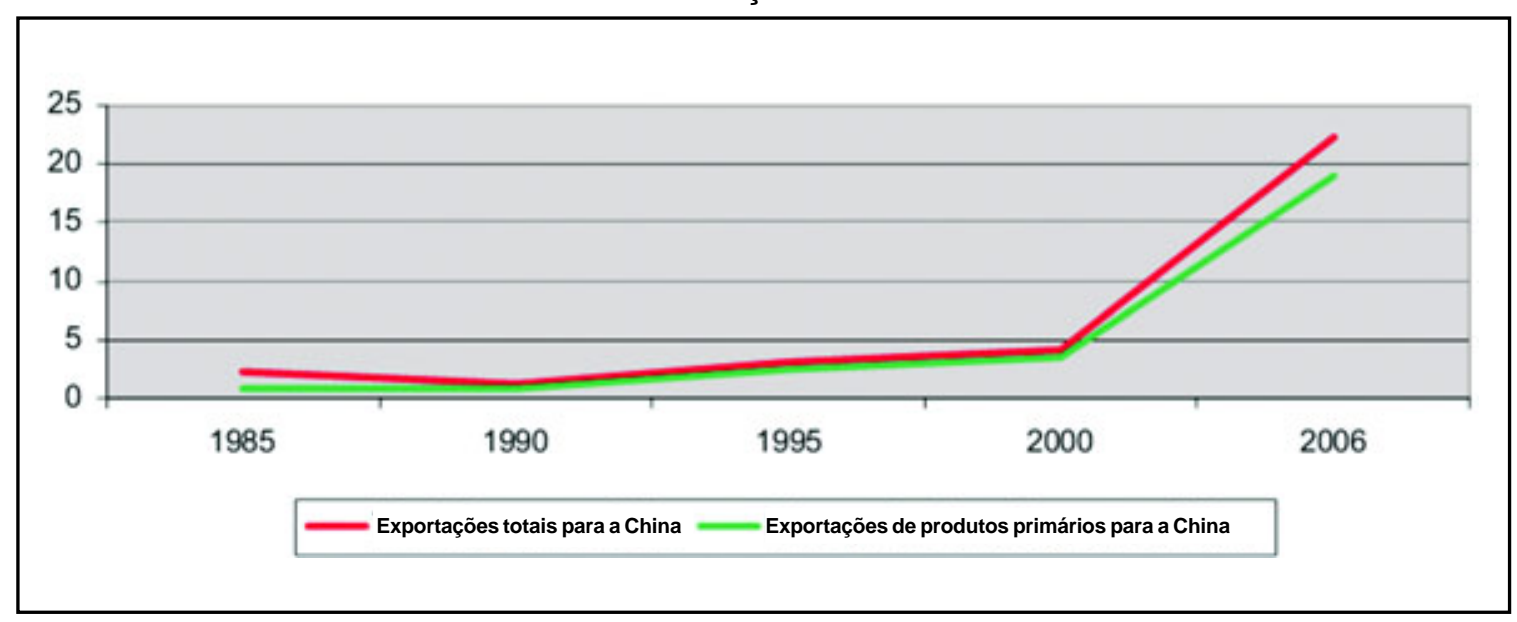

FONTE: Gallagher e Porzecanski (2009).

Antes de explorar as especificidades da maior demanda chinesa por commodities latinoamericanas, é importante notar o aumento da importância da China como destino para exportações latino-americanas desde o início da década de 2000. Por exemplo, em 2008, o total das exportações latino-americanas para a China ficou em torno de US\$ 47 bilhões, frente a US\$ 14,7 bilhões em 2004 (EGHBAL, 2009). Em geral, as exportações latino-americanas para a China expandiram-se por volta de $163 \%$ entre 2000 e 2008, com a maior parte desse crescimento ocorrido após 2002 (ver o Gráfico 2). Enquanto o impacto da crise financeira temporariamente enfraqueceu as vendas nessa relação comercial em rápida expansão, a demanda chinesa por exportações latino-americanas permaneceu forte em relação à demanda européia e norte-americana, e o comércio recuperou-se rapidamente, restituindo taxas de crescimento em níveis prévios à crise já em 2010. Por exemplo, apesar de um decréscimo de 2,2\% no primeiro bimestre de 2009, as exportações latino-americanas para a China registraram um aumento de $44,8 \%$ durante o mesmo bimestre, em 2010 (BÁRCENA et alii, 2010, p. 16).
Entretanto, os benefícios dos laços econômicos em expansão da América Latina com a China têm sido altamente concentrados em termos de geografia e setor econômico. Enquanto o volume das exportações latino-americanas em 2008 para a China constituíram apenas $5,6 \%$ das exportações gerais da região (comparado a 42,1\% para os Estados Unidos), para um número de países sul-americanos a China tornou-se seu principal destino exportador 6 . Por exemplo, a China tornou-se o mercado número um para as exportações chilenas e brasileiras e o destino número dois para exportações da Argentina, Peru, Costa Rica e Cuba. Embora seja prática comum referir-se a toda a América Latina (incluindo freqüentemente o Caribe) e suas relações com a China, as exportações "latino-americanas" para a China são na verdade dominadas por um pequeno número dos países da região envolvidos em um número limitado de commodities. Por exemplo,

6 Notando novamente a recuperação posterior à crise financeira de 2008, alguns estimam que a China possa receber acima de 19\% das exportações gerais latinoamericanas em 2010. Ver William Dey-Chao (2010, p. 48). 
em 2008, dez commodities em apenas seis países latino-americanos contaram por $74 \%$ das exportações da região para a China e 91\% das exportações gerais de commodities da região para a China (GALLAGHER \& PORZECANSKI, 2009, p. 5).

O comércio entre a China e a América Latina é, portanto, largamente caracterizado pela exportação de recursos naturais, especialmente metais, minérios e produtos agrícolas, da América Latina para a China. Em retorno, a China exporta, em larga medida, bens manufaturados de média e alta tecnologia (ver o Gráfico 1)7 . Como região, a América Latina presenciou um aumento consistente na exportação de produtos primários como parcela das exportações globais totais, indo de 26,7\% em 1999 para 38,8\% em 2009 (BÁRCENA et alii, 2010, p. 13). Para um número de países latino-americanos, a concentração de exportações de recursos naturais específicos em geral, e à China, em particular, é bastante acentuada. Por exemplo, no Chile, as exportações de commodities constituem quase $60 \%$ das exportações totais do país (BÁRCENA et alii, 2010, p. 13). Por sua vez, as exportações chilenas para a China são dominadas especificamente pelo cobre, que constitui $76 \%$ de suas exportações gerais para esse país (VOLPON, 2010, p. 79) ${ }^{8}$. Brasil, Venezuela, Colômbia e Peru também têm altas concentrações de exportações de commodities, notavelmente minério de ferro e petróleo, como percentual de suas exportações gerais para a China (VOLPON, 2010, p. 79-80; GARCÍA-HERRERO \& FUNG, 2008). A demanda da China, especialmente por minerais e

\footnotetext{
7 O México é a mais notável exceção a esse padrão, pela estrutura de sua economia exportadora manufatureira tender a colocar o país em competição com as exportações chinesas para o mercado norte-americano. Além disso, e diferentemente de muitas economias latino-americanas, o México possui um significativo deficit comercial com a China. Em 2008, a China constituiu 7,7\% das importações mexicanas, mas apenas $1 \%$ das exportações, implicando um deficit comercial geral superior a US\$ 24 bilhões (FERCHEN \& GARCÍA-HERRERO, 2010, p. 142-143). Como região, a América Latina, em 2008, teve um deficit comercial de 2,4\% com a China (EGHBAL, 2009).

8 Além disso, a contribuição das exportações de cobre chilenas para sua economia geral aumentou de 5,6\% do Produto Interno Bruto (PIB) em 1996 para 16,3\% em 2010. Ver Anderson (2010).
}

recursos energéticos, tem sido de longe o maior motor do crescimento da demanda global geral. Por exemplo, entre 2000 e 2008, a China foi responsável por dois terços do crescimento total global na demanda por aço e alumínio, e por um percentual ainda maior na demanda global por cobre (WYK, 2010, p. 6).

Assim, o retrato que emerge da relação comercial da China com a América Latina pode ser capturado por três pontos principais. Primeiro, os laços comerciais e de investimento entre a China e a América Latina cresceram rapidamente desde apenas o início do novo milênio. Segundo, a expansão de laços econômicos entre a China e a América Latina conferiu à China um papel de crescente proeminência como fonte de demanda para as exportações latino-americanas. Finalmente, os laços comerciais e de investimento entre a China e a América Latina são baseados na demanda chinesa por um conjunto relativamente limitado de recursos naturais, de um número relativamente pequeno de países, geralmente, sulamericanos. Esse retrato básico da natureza e direção das relações de comércio e investimento entre a China e a América Latina é geralmente consensual por observadores dentro e fora da China e da América Latina. Entretanto, diferentes avaliações sobre ao que está conduzindo essa relação e quais podem ser as implicações para ambos os lados são, ambas, mais abertas à interpretação e à controvérsia.

\section{O QUE CONDUZ A CRESCENTE RELAÇÃO COMERCIAL E DE INVESTIMENTO DA CHINACOM AAMÉRICALATINA?}

As explicações para a natureza da relação econômica entre a China e a América Latina baseada em commodities convergem a uma descoberta similar, mas problemática. Nomeadamente, a maioria das análises acadêmicas, midiáticas e de negócios dos laços econômicos chineses e latino-americanos apresentam uma correlação simples entre uma China em rápido crescimento e carente de recursos, de um lado, e uma América Latina rica em recursos, de outro. Detalhes do que está especificamente conduzindo a demanda chinesa por commodities latino-americanas são freqüentemente limitados e/ou simplistas. Ao contrário, o senso comum de que a América Latina simplesmente tem do que a China "precisa" substitui freqüentemente uma análise mais 
cuidadosa. Quando há uma análise mais detalhada dos recursos específicos da demanda chinesa, os argumentos para o que está conduzindo a demanda e sustentando sua estabilidade são muito freqüentemente subdesenvolvidas ou espúrias. É certamente verdadeiro, no sentido mais amplo, que o desenvolvimento econômico chinês está conduzindo a demanda do país por uma gama de recursos naturais da América Latina e outros lugares. Entretanto, é necessário entender as forças específicas que impulsionam a demanda chinesa se desejamos apreender o momento e a estabilidade das relações econômicas da China com a América Latina. Nesta seção eu detalho os tipos mais comuns de explicação para as exportações de commodities latino-americanas para a China, das afirmações mais óbvias das "forças básicas de mercado" para as mais sofisticadas análises de "ciclos de negócios".

Muitas explicações para os altos níveis de laços comerciais e de investimento entre a China e a América Latina enfatizam o papel das forças básicas de mercado. Uma versão comum desse argumento, descrevendo o aumento geral dos laços econômicos entre a China e a América Latina, simplesmente afirmam em linhas gerais que o crescimento chinês abasteceu a demanda para as exportações latino-americanas. Por exemplo, como afirmou o resultado de um grupo de estudos sobre as relações em expansão entre China e América Latina: "Em geral, o investimento e as atividades comerciais da República Popular da China na América Latina têm sido orientadas para assegurar acesso a produtos que a China tem necessidade para seu crescimento econômico" (CENTER FOR HEMISPHERIC POLICY, 2007). Outros simplesmente ligam o "crescimento econômico explosivo” chinês à demanda por commodities latino-americanas (RATLIFF, 2009). Nessa visão, os laços econômicos em expansão são simplesmente uma função básica da "necessidade" econômica chinesa rapidamente crescente por matérias primas oriundas da América Latina.

Uma versão levemente mais detalhada, mas ainda assim incompleta dessas explicações das “forças básicas de mercado” para a expansão dos laços China-América Latina, vai um passo além dos argumentos básicos de demanda-necessidade para especificar a importância das diferentes vantagens comparativas. Aqui, os analistas enfatizam o papel do apetite chinês por matérias primas para alimentar e sustentar o rápido crescimento econômico do país. Especificamente, esses argumentos focam a escassez de commodities da China (freqüentemente em termos per capita, em vez de absolutos) versus sua relativa abundância na América Latina. Como argumentou um analista de mercado: "A China é destituída da maior parte das principais commodities, incluindo minério de ferro, cobre, petróleo e madeira. O país simplesmente não pode continuar a crescer $9 \%$ ao ano [...] sem assegurar um suprimento estável de commodities” (BETHEL, 2009). Outra análise usa uma lógica similar para explicar o interesse chinês nas commodities latinoamericanas: "Os 30 anos de desenvolvimento econômico ininterrupto na China têm aumentado as necessidades do país por matérias primas para satisfazer a demanda por milhares de Empresas de Propriedade Estatal [SOEs, na sigla em inglês], corporações privadas e milhões de consumidores cada vez mais sofisticados. Isso é um resultado da escassez de recursos domésticos da China, somada à sua inabilidade de explorá-las e seu desejo de preservá-las para uso futuro (MINGRAMM et alii, 2009, p. 5) ${ }^{9}$. Assim, outra explicação de aparente senso comum para as demandas chinesas por matérias primas de países em desenvolvimentos ricos em recursos da América Latina (assim como da África e de outros lugares) é que a economia da China confia nessas injeções de commodities para manter um padrão de crescimento rápido longamente sustentável ${ }^{10}$.

Tais argumentos, conectando o crescimento chinês à sua “demanda" ou "requisitos" por recursos naturais, implícita ou explicitamente aceitam essa demanda como "natural”. Analistas

9 A Organização Econômica para Cooperação Econômica e o Desenvolvimento (OECD, na sigla em inglês) aplicou majoritariamente a mesma lógica em sua explicação do crescente apetite chinês por commodities africanas: “A demanda em expansão por energia e outros recursos naturais é essencial para sustentar o crescimento econômico da China, e a abundância desses recursos na África tem naturalmente determinado a recente evolução da relação econômica chinesa com a África” (OECD, 2008, p. 110; sem grifo no original).

10 Lógica parecida foi evocada em um experto atestado congressional: “A busca chinesa global pelas commodities necessárias para sustentar sua rápida expansão econômica forma o alicerce de sua relação com a América Latina” (ERIKSON, 2008) 
que enfatizam a crescente necessidade chinesa por recursos naturais freqüentemente apontam para três condutores específicos dentro da economia chinesa: (i) o crescimento populacional; (ii) a urbanização, que por sua vez é freqüentemente ligada ao desenvolvimento da propriedade e da infraestrutura; (iii) a crescente classe média consumidora (MINGRAMM et alii, 2009, p. 1; ZWEIG, 2010, p. 40). Por exemplo, um estudo aponta para a "necessidade [chinesa] progressiva de matérias-primas, mercados e alimento para sustentar [...] o crescimento e satisfazer as crescentes demandas consumidoras" (RATLIFF, 2009, p. 1) $)^{11}$. No entanto, a demanda chinesa por grandes quantidades de matérias-primas durante o período de crescimento das relações comerciais e de investimento com a América Latina foram qualquer coisa, menos naturais. Portanto, análises e projeções baseadas em hipóteses falhas e em entendimento inadequadamente detalhado dos condutores específicos da demanda chinesa podem facilmente levar à confusão e a expectativas desapontadoras para todas as partes envolvidas.

Entretanto, embora ainda ignorando alguns detalhes importantes, uma última linha de explicações para as relações econômicas em expansão da China com a América Latina de fato aproxima-se muito mais de um conhecimento mais detalhado. Essa visão reconhece a natureza pró-cíclica dos laços comerciais sino-latinoamericanos. Por exemplo, alguns analistas notaram que os ciclos de negócios chineses, e subseqüentemente a demanda por matérias primas, pode ser "sincronizado" com exportações latino-americanas desses materiais. Em particular, alguns têm demonstrado as conexões detalhadas entre fluxos específicos de commodities da América Latina para a China. Essa pesquisa, não

11 Ratliff, explicando os interesses "pragmáticos” da China no comércio de commodities expandido com a América Latina, enfatiza que seu objetivo número um é “comprar commodities indo do petróleo e o ferro ao cobre e sementes de sofá que são necessários ao desenvolvimento da China e para satisfazer as demandas populares por uma vida melhor" (RATLIFF, 2009, p. 7). Como argumento a seguir, as demandas chinesas por recursos minerais e energéticos em expansão precisamente não é almejada para satisfazer demandas consumidores populares, mas, em vez disso, para alimentar o (sobre)desenvolvimento industrial pesado. surpreendentemente, mostrou uma correlação positiva entre o aumento do grau de especialização da exportação de commodities latino-americanas e as exportações para a China (CALDERÓN, 2009). Alguns economistas e consultores de commodities têm sido ainda mais explícitos em notar que o particular "ciclo de negócios” chinês que pode estar em operação aqui tem conduzido a uma "explosão de commodities" (VOLPON, 2010; AVENDAÑO \& SANTISO, no prelo).

No entanto, a ênfase em uma explosão (boom) chinesa, ou conduzido pela demanda chinesa ou pela ascendente no ciclo de negócios, está freqüentemente conectada a uma avaliação otimista da continuidade, próxima ao médio prazo, da forte e consistente demanda chinesa por commodities latino-americanas (e outros países ou regiões ricos em recursos). Uma dessas linhas de raciocínio estabelece uma conexão comparativa entre crescimento e experiências de demanda de recursos de outros países de rápido desenvolvimento do Leste Asiático, como o Japão e a Coréia do Sul. Partindo de comparações históricas explícitas de crescimento consumidor e industrial nesses "estados desenvolvimentistas" pobres em recursos, alguns argumentam que a explosão de commodities liderada pela China (pelo menos para certos produtos como minério de ferro e cobre) pode ser mantida por pelo menos outras duas décadas (MINGRAMM et alii, 2010). Tais comparações tendem a ignorar os fatores políticos e econômicos específicos dirigindo a própria trajetória chinesa de desenvolvimento, focando em vez disso apenas a parte superior do ciclo de desenvolvimento e a demanda de recursos nesses outros países do Leste Asiático. Se uma ascendente na demanda chinesa está dirigindo o crescimento em exportações de commodities da América Latina, é simplesmente lógico que qualquer descrédito ou instabilidade nessa demanda terá um efeito negativo no volume de exportação e/ou nos preços.

Ultimamente, no coração de uma vasta maioria de explicações para a expansão do comércio entre a China e a América Latina há um consenso aparentemente de que a trajetória chinesa ascendente implica exportações de commodities latino-americanos sempre crescentes e, pela maior parte, cada vez mais valiosas, para abastecer essa ascensão. Especificamente, essa noção de senso comum está baseada na seguinte linha de raciocínio: a economia chinesa está crescendo 
rapidamente, e porque a China é relativamente escassa em certos recursos naturais, é óbvio que ela buscou fontes dessas commodities em países ricos em recursos como a América Latina. O resultado foi a crescente relação comercial e de investimento baseada em commodities com a América Latina. A questão de por que a China somente começou a demandar commodities em quantidades cada vez maiores no começo da década de 2000, se o país tem crescido a uma média acima de $9 \%$ desde o fim da década de 1970, quase nunca é colocada. Além disso, mesmo a maior parte daqueles que reconhecem a natureza "cíclica" da relação não exploram os fatores políticos e econômicos específicos dirigindo a explosão da demanda chinesa. Isso é um descuido crucial porque, ao menos que entendamos melhor a natureza e o momento da explosão de commodities dirigida pela China, não podemos avaliar efetivamente a extensão dos efeitos que podem seguir-se se e quando a explosão terminar.

\section{AVALIANDO AS CONSEQUÊNCIAS: COMPLEMENTARIDADE VERSUS DE- PENDÊNCIA}

Ao mesmo tempo em que há uma gama de explicações para a rápida expansão do comércio chinês baseado em commodities e as relações de investimento com a América Latina, todas girando em torno da idéia de que o crescimento chinês está puxando a América Latina consigo, há controvérsia acerca das implicações dessa relação florescente . Em particular, existem duas visões contrastantes sobre os laços do crescimento econômico chinês com a América Latina: a primeira enfatiza a complementaridade e o benefício mútuo enquanto a segunda demonstra preocupação com relação a uma repetição de padrões históricos disfuncionais de dependência. Entretanto, nem a perspectiva otimista da "complementaridade" nas relações China-América Latina nem a visão pessimista da "dependência" capturam a dinâmica específica e mais relevante que conduz a explosão chinesa baseada em commodities. Avaliar essas perspectivas concorrentes requer uma compreensão mais detalhada e diferenciada de alguns dos fatoreschave da demanda chinesa por um número de commodities latino-americanas, especialmente os minerais.

\section{IV.1. Complementaridade}

Como detalhado acima, a maioria das explicações para os crescentes laços de investimento e comércio da China com a América Latina relacionam a demanda chinesa por recursos naturais à oferta latino-americana desses recursos. A abundância de recursos da América Latina aparenta, então, complementar a escassez de recursos da China. Tal foco em uma complementaridade natural é também a base para os julgamentos mais otimistas acerca da natureza e do desenvolvimento futuro dos laços econômicos e políticos entre a China e a América Latina. Ademais, tais visões baseadas na complementaridade servem de fundamento para a preponderância de altas, e ainda ascendentes, expectativas quanto ao desenvolvimento futuro dos laços comerciais e de investimento entre China e América Latina. A política oficial de governo da China, apoiada por think tanks chineses centrais especializados nos vínculos latino-americanos, é a mais óbvia proponente da idéia de complementaridade como o quadro correto para a compreensão dos laços China-América Latina. Concomitantemente, muitos líderes de negócios e membros do governo, especialmente nos países latinoamericanos que são ricos em commodities, também são rápidos em enfatizar as complementaridades fundamentais da demanda chinesa e da oferta latino-americana.

Em sua diplomacia pública, a China usa a linguagem do "ganha-ganha" "win-win" e do "benefício mútuo" para ressaltar os benefícios positivos para a China e para a América Latina por seus vínculos econômicos emergentes. Outra parte basilar dessa estrutura de relações econômicas como fundamentalmente complementares é baseada na lógica que as relações chinesas com a América Latina são "SulSul”"12. Cada um desses conceitos é consagrado no "Documento de Política para a América Latina e o Caribe” chinês de 2008, que buscou esclarecer os fundamentos e objetivos chineses de suas relações com a América Latina. Importantes

12 Não deve ser surpresa que o governo chinês use essa linguagem na sua diplomacia pública, visto que ele tem um duradouro investimento na idéia de laços “Sul-Sul” (embora não necessariamente com ênfase na América Latina) desde a Era Maoísta. Para mais sobre o histórico da diplomacia pública “Sul-Sul” da China, ver Monica Hirst (2008). 
acadêmicos chineses que estudam a América Latina na Academia Chinesa de Ciências Sociais (CASS, na sigla em inglês) e em outros think tanks também, consistentemente, retratam a relação sino-latino-americana nos mesmos termos de benefício mútuo. Por exemplo, o vice-Diretor do Instituto de Estudos Latino-Americanos da CASS argumentou que "tanto a China quanto a América Latina pertencem ao Terceiro Mundo e a cooperação entre os lados beneficiará a paz mundial e o desenvolvimento" (SHIXUE, 2005, p. 15$)^{13}$. Assim, o governo chinês e alguns dos seus principais analistas acadêmicos de relações com a América Latina usam a linguagem da complementaridade para enfatizar uma estabilidade e uma igualdade fundamentais carregadas de similares históricos e metas de desenvolvimento.

A linguagem da complementaridade e benefício mútuo é retribuída por alguns, embora claramente não todos, os líderes latino-americanos bem como por alguns essenciais institutos de pesquisa daquele continente ${ }^{14}$. Em particular o governo brasileiro, sob a liderança do Presidente Luiz Inácio Lula da Silva, adotou a linguagem dos vínculos "Sul-Sul” para descrever as relações sinobrasileiras que crescem rapidamente. Além da associação em comum ao G20, sem mencionar ao ainda mais exclusivo BRICs, o Brasil tem promovido sua relação com a China como tanto mutuamente benéfica quanto um meio de promover formas de liderança internacional alternativas (aos EUA) ${ }^{15}$. Por sua vez, um dos

13 A avaliação de Shixue do que conduziu os vínculos econômicos da China à América Latina encaixa-se nessa positiva pespectiva de complementaridade. Ele diz que “a China também enfrenta uma falta de recursos naturais, em grande parte devido à sua enorme população e ao seu rápido crescimento econômico" (SHIXUE, 2008, p. 34).

14 De todos os grandes países latino-americanos o México é o menos provável de ver a relação nestes termos. Duas das principais razões são porque o México tem um grande déficit comercial com a China e porque ele compete com a China como base manufatureira para exportações para o mercado norte-americano.

15 Para uma abrangente visão global das relações comerciais, de investimento e diplomáticas sino-brasileiras sob a perspectiva brasileira, ver Dey-Chao e Wyk (2010, p. 50-51). Para mais sobre os detalhes e os desafios da cooperação sino-brasileira como parte do BRICs, ver Michael Glosny (2010). principais think tanks econômicos da América Latina, a Comissão Econômica para a América Latina e o Caribe (Cepal), elogiou o papel positivo dos laços comerciais sinolatino-americanos à luz da crise financeira. Ambos os relatórios da Eclac de 2009 e de 2010, amplamente citados na imprensa chinesa, argumentaram que a forte demanda chinesa por commodities latinoamericanas teve um papel fundamental para minimizar os efeitos negativos da crise global financeira e para fornecer um forte motor que conduzisse uma recuperação regional rápida (LATIN AMERICA MUST TAKE, 2009; BÁRCENA et alii, 2010). Conforme o relatório da Cepal de 2009 declarou, "de certa forma, o mercado interno chinês resgatou as exportações latino-americanas" (LATIN AMERICA MUST TAKE, 2009). Assim a visão de uma relação sinolatino-americana complementar e, portanto, mutuamente benéfica, é um tema central não só na diplomacia pública chinesa mas também entre importantes líderes e centros de pesquisa latinoamericanos.

A linguagem dos laços "Sul-Sul", promovida pelo governo chinês e pelos think tanks e geralmente retribuída por suas contrapartidas latino-americanas, tem um papel central no estabelecimento de expectativas sobre a natureza e o futuro desenvolvimento das relações econômicas e políticas sino-latino-americanas. Algumas dessas expectativas são explícitas, enquanto outras são mais implícitas. Por definição, se a interação da China com a América Latina é "Sul-Sul”, e portanto entre a China como um país em desenvolvimento e a América Latina como uma região de países em desenvolvimento, ela deveria ser qualitativamente distinta das relações “Norte-Sul”. As relações “Norte-Sul” são assim o contraste implícito (e apenas às vezes mais explícito). Seja a referência às relações EstadosAmérica Latina, seja às relações Europa-América Latina, as relações Norte-Sul situam-se, na comparação histórica, como relações de exploração e de desigualdade. Portanto, se os laços econômicos e políticos sino-latinoamericanos são Sul-Sul, o argumento que eles são inerentemente também de vínculos "ganha-ganha" deve ser por causa de sua natureza mais igual, de não exploração e, em última análise, estável. Alguns críticos dessa perspectiva ressaltam preocupações sobre a real igualdade da relação. Em contraste, este artigo realça os riscos de 
superestimar a probabilidade de um infinito crescimento chinês de commodities.

\section{IV.2. Dependência}

É irônico que a Cepal, uma vez o berço institucional de uma das principais correntes da teoria da "dependência” na América Latina, carregaria uma mensagem tão positiva acerca da complementaridade do comércio commodity-pormanufaturas sino-latino-americanas. Durante a alta fase de industrialização de substituição de importações (ISI), a Cepal era sinônimo do pensamento do economista argentino Raúl Prebisch, cuja pesquisa serviu de base para muitas políticas de ISI dentro da América Latina e além ${ }^{16}$. Ademais, juntamente com outros influentes estudiosos da América Latina como Andre Gunder Frank ("desenvolvimento do subdesenvolvimento") e Fernando Henrique Cardoso e Enzo Faletto ("desenvolvimento dependente”), Prebisch e a Cepal tiveram um papel instrumental em criticar a inserção latino-americana na economia mundial, em fins do século XIX e início do século XX, como, principalmente, um fornecedor de commodities de recursos naturais para os países em rápida industrialização na América do Norte e na Europa $^{17}$.

Uma das reivindicações mais famosas, mas também polêmicas, de Prebisch era que a dependência histórica latino-americana por exportações de commodities em troca de importações manufaturadas do mundo desenvolvido implicava um desequilíbrio estrutural em "termos de troca” (TdT) pelo qual o valor das exportações de commodity tendia a deteriorar-se em relação às importações manufaturadas (PALMA, 1978).

Baseado na idéia de que a região precisava rejeitar os modelos de desenvolvimento liberais e estáticos de vantagem comparativa que muito dominaram através do fim do século XIX ao início

\footnotetext{
16 Para mais sobre a influência de Prebisch nas conexões teóricas e políticas entre a “dependência” e o ISI assim como o apelo mais amplo de ambos para muitos países em desenvolvimento na era posterior à II Guerra Mundial, ver Frieden (2006).

17 Para um resumo clássico das variadas permutações da “dependência” como um conceito teórico e ideia política, ver Palma (1978).
}

do século XX, o resultado de parte do pensamento da dependência foi como os governos latinoamericanos poderiam promover o desenvolvimento e a industrialização por meio do envolvimento mais direto do Estado na economia. É importante ter em mente que o quadro histórico imediatamente anterior a essa tradição teórica e política foi o colapso quase completo do modelo de desenvolvimento de exportações de commodities da região na esteira da I Guerra Mundial, da Grande Depressão e da II Guerra Mundial. Assim, na era posterior à II Guerra até a década de 1970, muito do pensamento de desenvolvimento na região da América Latina era dominado por como afastar-se de uma dependência excessiva da exportação de commodities de recursos naturais para um modelo mais estável e, portanto, sustentável de desenvolvimento industrial. A teoria da dependência, como quintessência da "tradição crítica" latino-americana, pode ter sido, desde então, largamente posta de lado por muitos como um artefato histórico, mas não muito tempo atrás ela tinha grande força tanto entre os círculos acadêmicos quanto nos políticos ${ }^{18}$.

Hoje, quer eles ressaltem explicitamente ou não a tradição de dependência latino-americana, muitos daqueles que se preocupam com o padrão de relações econômicas latino-americanas com a China referenciam elementos da crítica original de dependência. As mais comuns entre as críticas do tipo "dependência” são aquelas que rejeitam as imagens positivas da complementaridade e, ao invés disso, expressam preocupação com relação à natureza do comércio da América Latina com a China, em que as exportações são de commodities e as importações são de bens manufaturados. Outras vão além ao argumentar que a China, por meio de investimentos diretos em infraestrutura para facilitar o transporte das exportações de recursos naturais da América Latina, assumiu um papel uma vez tido por países como a Grã-Bretanha no séxulo XIX. Por exemplo, alguns críticos como o economista brasileiro Delfim Netto já referiram-se à relação sino-latino-americana como uma norma de imperialismo ou colonialismo chinês (PHILLIPS, 2010 $)^{19}$. Mais freqüentemente, no

18 Para um tratamento da extinção da teoria da dependência e da "tradição crítica” latino-americana de maneira mais geral, ver Palma (2010).

19 Acusações de que o comportamento chinês de comércio e investimento são coloniais ou "neocoloniais" em natureza 
entanto, argumentos do tipo “dependência” são colocados no nível do que é tido como a natureza assimétrica ou desequilibrada dos laços de comércio e de investimento entre a China e a América Latina.

Alguns exemplos recentes demonstram como os temas de dependência são utilizados para descrever a relação econômica da América Latina com a China. Por exemplo, um relatório argumenta que "o padrão existente de comércio [entre a China e a América Latina] revela assimetrias crescentes que estão aprofundando a dependência histórica latino-americana por exportações de commodities de baixo valor agregado" e, portanto, que a “relação assumiu um tom ‘Norte-Sul”” (VOLPON, 2010, p. 79-80).

Outras, ecoando as preocupações dos dependentistas originais, salientam as distorções domésticas e internacionais que resultam da natureza commodities-manufaturados da relação comercial sino-latino-americana. Evan Ellis (2008), autor de um livro sobre as relações ChinaAmérica Latina, preocupa-se que, dentro dos países latino-ame-ricanos, o retorno corrente das exportações de commodities é apropriado, principalmente, por elites econômicas ou políticas. Ao mesmo tempo, Ellis também se preocupa com o fato de que, em um nível comparativo internacional, as exportações chinesas de manufaturados são um condutor mais estável para o crescimento da própria China do que as exportações de commodities o são para a América Latina (idem, p. 286-288). Assim, o que alguns caracterizam como uma relação mutuamente

são mais normalmente ouvidos com relação à África. Para um argumento sobre como conceitos do gênero de "neodependência” ou "interdependência pós-colonial” podem lançar luz sobre a relação da China com a África, ver Rupp (2008). Apesar das críticas, certos líderes governamentais e corporativos acolhem um potencial aumento do investimento chinês na América Latina em ferrovias, autoestradas, pontes e infraestrutura de portos. Para mais sobre a visão positiva brasileira acerca de potencial investimento futuro da China em infraestrutura no país, ver The Beijing Axis (2010). Um aumento do desenvolvimento de infraestrutura chinesa na região também tem o potencial de produzir uma espécie de efeito de "aprisionamento" pelo qual a infraestrutura financiada e construída pela China cria ligações com a América Latina que poderiam resistir aos choques de curto prazo na demanda ou na oferta (eu agradeço a Jean-Marc Blanchard por essa sugestão). benéfica e complementar é, para outros, tanto "assimétrica" como próxima demais dos padrões historicamente traumáticos de desenvolvimento que muitos na região trabalharam tão duramente por tanto tempo para superar.

Entretanto, tão importantes quanto alguns desses argumentos relacionados à dependência, para entender como as relações sino-latinoamericanas são avaliadas, são argumentos relacionados a como a América Latina pode ser capaz de controlar mais efetivamente os benefícios de sua atual relação de exportação de commodities com a China. Os relatórios da Comissão Econômica para a América Latina e o Caribe (Cepal) acima mencionados, que ressaltam como a demanda chinesa por exportações latinoamericanas teve um papel crucial ao ajudar a América Latina a resistir à crise financeira, são indicativos de como mesmo os céticos latinoamericanos podem ver um lado positivo naquilo que foi, por muito tempo, visto como padrões de desenvolvimento historicamente disfuncionais.

Outro estudo importante nesse aspecto, embora focando mais diretamente nas críticas à dependência, é um relatório do Banco Mundial sobre ciclos de expansão e contração de commodities na América Latina (SINNOTT, NASH \& DE LA TORRE, 2010). O relatório vai muito além das críticas à dependência acima descritas ao argumentar que os ganhos privados e governamentais advindos da explosão de exportações baseadas em recursos naturais, se canalizados e utilizados de maneira efetiva, podem fortalecer um desenvolvimento sustentável de longo prazo na região. Focando as críticas anteriores quanto à dependência e à explosão de commodities, o relatório aponta que o argumento dos termos de troca de Prebisch pode ser contrabalançado por políticas cambiais apropriadas e diversificação de exportação (idem, p. 48-50, 60).

Não obstante, ao tornar público o relatório, um de seus autores e Economista-Chefe do Banco Mundial, Augusto de la Torre, chama atenção para uma hipótese elementar sobre a qual esses outros achados mais otimistas foram baseados: "presumindo que a demanda asiática por exportação de soja da Argentina, minério de ferro do Brasil, cobre do Chile, peixes e minerais do Peru e outras commodities latino-americanas continue, a região está em uma ótima posição para lucrar sobre seus recursos naturais” (AGUILAR, 
2010). Entretanto, suposições de tal demanda chinesa alta e sustentada, que se igualam a uma fé na continuidade de uma explosão de commodities guiadas pela China, têm o potencial real de conduzir a expectativas frustradas.

V. CHINA E A EXPLOSÃO DAS COMMODITIES: FONTES INTERNAS E CONSEQUÊNCIAS EXTERNAS

A discussão acima realça a concordância ampla e aparentemente o senso comum de que a robusta relação de comércio da América Latina com a China é uma simples função do rápido desenvolvimento da segunda e sua necessidade por recursos naturais que alimentem seu desenvolvimento. A única controvérsia real parece girar em torno das conseqüências a longo prazo para o desenvolvimento latino-americano: os laços econômicos da China com a América Latina são complementares e, portanto, uma fonte confiável para o crescimento latino-americano ou são laços de dependência e, portanto, de alguma forma desigual ou instável? No geral, a visão otimista das relações China-América Latina como complementares parece ser ascendente, com vozes críticas ouvidas na maior parte de países que não se beneficiaram com as exportações expandidas de commodities para a China ou daqueles que se agarram ao que podem parecer teorias ultrapassadas de dependência. Onde as perguntas de fato surgem sobre os benefícios relativos dessa relação, elas são normalmente centradas sobre se os ganhos com o comércio baseado em commodities são divididos igualmente entre China e América Latina, bem como dentro de certos países latino-americanos.

No entanto, nós não podemos realmente começar a avaliar o debate complementaridadedependência sem uma compreensão mais apurada dos precisos condutores da demanda chinesa e como esses condutores estiveram conectados a mudanças mais amplas na trajetória de desenvolvimento da China nos últimos anos. Nós devemos perguntar: por que a China veio, e ainda continua, a "precisar" de certos recursos latinoamericanos em quantidades cada vez maiores depois de decolar em um ponto específico no tempo há menos de uma década? Para que consigamos fazer isso, nós devemos olhar para certas tendências na economia política doméstica chinesa, em particular, tendências na trajetória de desenvolvimento do país, que coincidiram com a expansão chinesa de importações de commodities da América Latina e outras regiões. Em outras palavras, nós devemos abrir a caixa preta da demanda chinesa por recursos naturais. Ao fazermos isso, confrontamo-nos com uma figura muito mais complexa do que uma simples e aparentemente imparável trajetória ascendente baseada em uma demanda chinesa saudável e em expansão.

Em particular, qualquer avaliação das perspectivas de longo prazo das relações econômicas China-América Latina deve estar enraizada em uma clara compreensão de como um incremento na produção industrial pesada da China desempenhou um papel fundamental no desencadeamento de uma explosão global de commodities por recursos minerais e energéticos para alimentar essa produção. Assim, a trajetória de desenvolvimento chinesa passou por mudanças significativas justamente no momento em que o comércio com a América Latina decolou. No entanto, tais mudanças, em grande parte, não foram previstas nem intencionais.

Enquanto o crescimento da China continuou em altas taxas, mesmo em meio à crise financeira global, uma série de “desequilíbrios” só continuaram a crescer e podem, em algum momento, desempenhar um papel no término da explosão de commodities. Se a explosão global de commodities teve sua origem nas transformações dentro da própria China, seu fim possivelmente terá raízes nas forças econômicas e políticas domésticas chinesas. Quer o resultado das correções de mercado ou de política de governo, quer uma combinação das duas, um número de mudanças já estão em andamento e podem alterar fundamentalmente a demanda chinesa por uma gama de commodities globais. Mesmo que a explosão de commodities guiada pela China não venha a falir totalmente, a possibilidade de que a demanda chinesa pode e vai experimentar alta volatilidade em resposta à combinação das forças do mercado e das políticas de governo está sempre presente.

VI. O MODIFICADO CAMINHO DE DESENVOLVIMENTO DA CHINA: AS IMPLICAÇÕES DAS EXPLOSÕES DOMÉSTICA E INTERNACIONAL

Desde a primeira parte da década de 2000, a economia chinesa sofreu uma profunda série de 
mudanças. Essas mudanças afetaram não só o padrão de desenvolvimento doméstico chinês mas também afetaram significativamente a relação econômica e política da China com a comunidade global. Muitos economistas apontam que desde os primeiros anos do século XXI a economia doméstica da China e sua relação com a economia global tornaram-se crescentemente "desequilibradas"20. Enquanto o crescimento total continuou em ritmo acelerado a uma média de quase $10 \%$, outros componentes do padrão de desenvolvimento chinês mudaram dramaticamente. Fora da China, entre as mais discutidas dessas mudanças estão o aumento do superavit comercial chinês e, com ele, da participação do país em reservas estrangeiras ${ }^{21}$. No entanto, dentro da China é o aumento no desenvolvimento industrial pesado, muito do qual tem ido alimentar a rápida urbanização e o desenvolvimento de infraestrutura conduzidos pelo Estado, que tem impactado no volume e no preço de entrada de commodities latino-americanas essenciais (especialmente minerais e energia). Simplificando, a América Latina se vinculou a um boom de commodities conduzido pela China, que por seu turno foi abastecido em parte substancial por uma decolagem na produção industrial pesada chinesa.

Desde o início de suas políticas de "reforma e abertura” ao final dos anos 1970, a China distanciou-se do modelo de desenvolvimento industrial pesado de capital intensivo do "Grande Salto” da Era de Mao em direção a uma dependência de manufatura leve de trabalho intensivo ${ }^{22}$. No entanto, logo após a virada do

20 Avaliar esses desequilíbrios tornou-se um ponto de contenda dentro e fora da China. Para exemplos de pesquisa relacionada, ver Yongding (2007), McKinnon e Schnabl (2009) e Pettis (2010a).

21 Enquanto a China experimentou de modo consistente superavits comerciais entre $1 \%$ a 1,5\% do PIB, de 1982 a 2002, os excedentes dispararam na última década. Iniciando por volta de 2003, os superavits começaram a subir e, em 2007, atingiram 11\% do PIB (ANDERSON, 2009, p. 25). Com a conta de capital fechado da China e a taxa de câmbio controlada, esses excedentes traduziram-se em reservas cambiais, rapidamente crescentes, de quase US\$ 2,5 trilhões em 2009. Essa cifra representa cerca de 50\% do PIB da China e aproximadamente 5-6\% do PIB global, que em termos históricos só foi igualado pelos Estados Unidos na década de 1920 e pelo Japão no final da década de 1980 (PETTIS, 2010b).

22 Para uma explicação do modelo do "Grande Impulso" milênio a China começa uma reversão dramática, inesperada e não planejada em direção a uma produção industrial pesada. Entre 1985 e 2002 o crescimento industrial chinês foi constante, mas, depois de 2002, a economia da indústria pesada da China experimentou uma explosão extraordinário. A proporção total do PIB foi responsável por praticamente todo esse aumento. No espaço de cinco anos, o tamanho relativo da produção industrial pesada (aço, metais, químicos, energia eólica, produção de papel e todos os setores intensivos em eletricidade) na economia praticamente triplicou. Isso não teve precedentes na história econômica da China (CÂMARA EUROPÉIA DE COMÉRCIO, 2009).

Evidências dessa transformação começaram a aparecer por volta do ano de 2001, quando a China testemunhou um aumento inesperado da intensidade e do crescimento da demanda total de energia ${ }^{23}$. Durante todo o período de reforma do final dos anos 1970 até 2011, a intensidade energética da China esteve em declínio na medida em que o país passava da indústria pesada para a manufatura leve ${ }^{24}$. Enquanto o país cresceu a uma taxa média acima de $9 \%$ durante esse período, o crescimento energético permaneceu à média de apenas 4\%. Por volta de 2001 esse cenário começou a mudar conforme a intensidade de energia acentuou-se, e o aumento da demanda por energia disparou para $13 \%$ ao ano, ultrapassando assim o crescimento global do PIB (ROSEN \&

de desenvolvimento industrial sob o poder de Mao, ver Naughton (2008).

23 A ascensão da China em 2001 à Organização Mundial de Comércio (OMC) foi, de modo claro, parte de um esforço estratégico maior para inserir firmemente a China na economia global. Juntamente com os esforços chineses posteriores à crise financeira do Leste Asiático para manter reservas em moeda suficientes para permitir uma resposta política independente para potenciais choques monetários, a entrada da China na OMC é notável como parte de um esforço político concertado para dar continuidade à reforma da economia chinesa. Mais pesquisas precisam ser conduzidas sobre a conexão entre os fatores políticos e econômicos por trás das mudanças dramáticas na trajetória de desenvolvimento da China no início dos anos 2000.

24 Para um claro resumo da reversão da China para um padrão de desenvolvimento de indústria pesada intensiva em energia, ver Rosen e Houser (2007). Para mais sobre a intensidade energética chinesa, ver Andrews-Speed (2009). 
HOUSER, 2007, p. 6-7) ${ }^{25}$. O fator-chave que conduziu o aumento na intensidade e na demanda energética foi o incremento na manufatura industrial pesada de produtos como o aço, o cimento e os químicos (ver o Gráfico 3).
Conforme a produção da indústria pesada dentro da China subiu, também subiu a demanda por uma gama de commodities de insumos importados para alimentar a demanda florescente.

\section{GRÁFICO 3 - VALOR AGREGADO INDUSTRIAL EM RELAÇÃO AO PIB (1995-2005)}

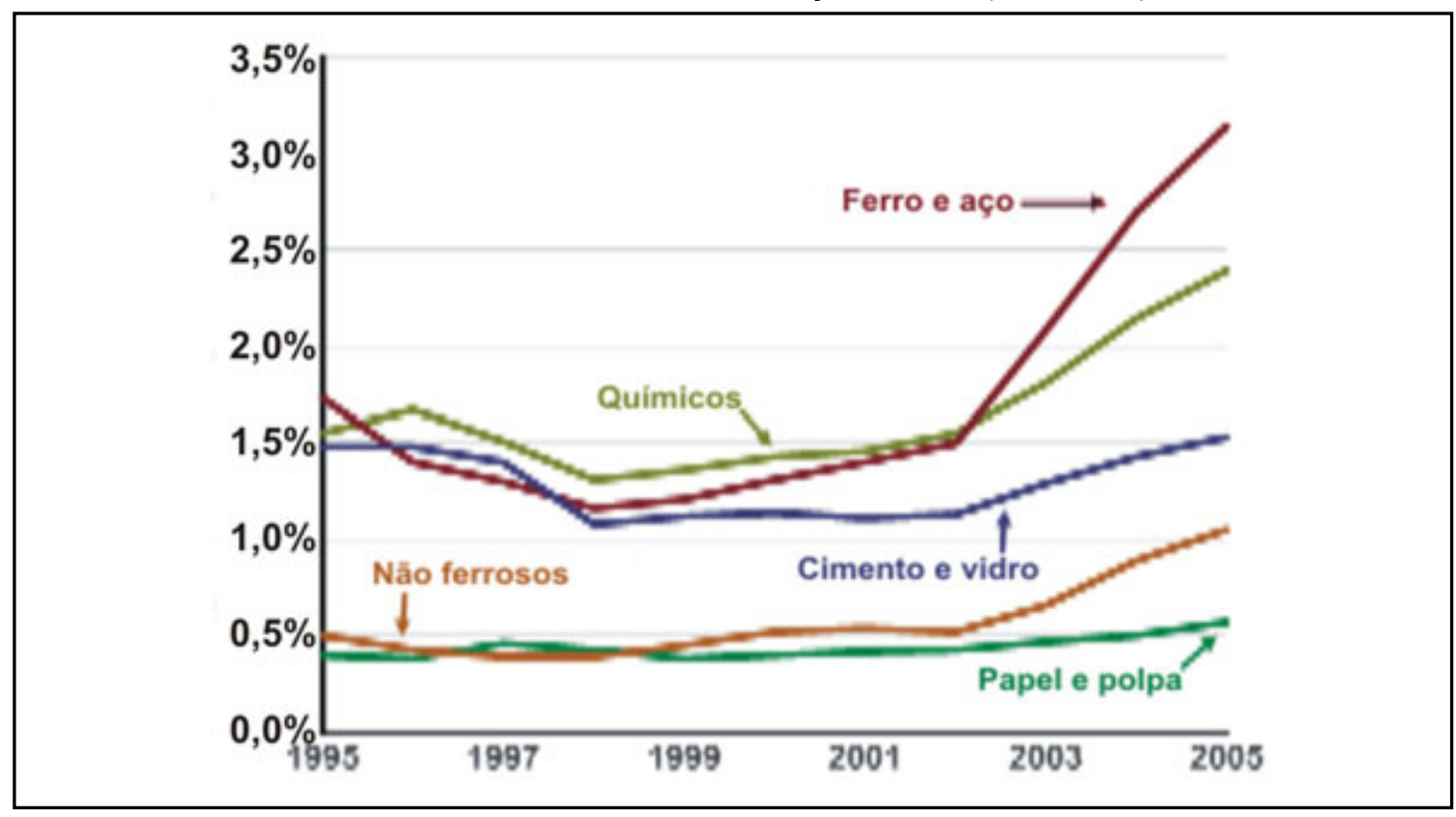

FONTE: Rosen e Houser (2007).

O caso do aço e do minério de ferro exemplifica de maneira clara como o rápido aumento na produção doméstica chinesa de indústria pesada levou a uma explosão global em commodities minerais específicas ${ }^{26}$. Apenas entre 2002 e 2005, a produção chinesa de ferro e aço, como porcentagem do PIB, aumentaram de aproximadamente $1,5 \%$ para mais de $3 \%$ (idem, p. 8). Começando no princípio dessa década, a

25 Dentro da China, alguns estudiosos e autoridades expressaram-se com alarme sobre como o rápido aumento na demanda por recursos energéticos exacerbou preocupações de segurança energética. Por exemplo, ver Daojiong (2006).

26 Além de ser o principal consumidor de minério de ferro, em 2008 a China tornou-se o consumidor número um de cobre, alumínio, níquel, zinco e estanho e o número dois no consumo de petróleo. Por causa da crise financeira a demanda chinesa por commodities enfraqueceu-se no início de 2009 mas recuperou-se rapidamente depois disso. Ver Wyk (2010, p. 6). produção chinesa de aço bruto cresceu anualmente a uma taxa de 18,3\% (em comparação com 4,3\% no resto do mundo) (WYK, 2010, p. 7). A importadora líquida de aço em 2002, a China tornou-se a maior produtora mundial de aço em 2007, respondendo por 37\% da produção mundial de aço bruto daquele ano (YONGDING, 2009, p. 8). E em 2010 a China já era responsável pela produção de quase metade do aço do mundo (WYK, 2010, p. 7). Para colocar em perspectiva a velocidade dessa transição, em 2002 a importação chinesa de aço ultrapassava sua exportação em 450\%, mas em 2006 a exportação excedia a importação em $230 \%$ na medida em que a China se tornou o maior produtor e exportador de aço no mundo (ROSEN \& HOUSER, 2007, p. $13)^{27}$. Enquanto a maior parte dessa rápida

27 Como o economista do UBS Jonathan Anderson aponta, a transição da China para uma posição de exportador líquido de aço implicou primeiro o controle das fatias de mercado estrangeiras dentro da China e então a expansão 
expansão na produção alimentou a crescente demanda doméstica, o setor de aço da China se tornou cada vez mais orientado para a exportação, com cerca de $11,5 \%$ da produção indo para a exportação em 2008 (KPMG, 2009, p. 7).

Essa explosão na produção chinesa de aço, por sua vez, desencadeou um aumento na demanda por minério de aço, com a China agora consumindo um total de 70\% das exportações de minério de aço do mundo (GARNAUT, 2010). Esse aumento na demanda por minério de ferro influenciou diretamente as fortunas dos cofres das empresas e dos governos nos principais exportadores latino-americanas como Brasil e Peru $^{28}$. A China é, de longe, o maior importador do minério de ferro brasileiro e a Vale do Rio Doce, a maior produtora de minério de ferro do mundo, ficou no topo da onda da crescente demanda chinesa, lucrando exponencialmente ${ }^{29}$. Em parte isso se explica porque o aumento na demanda por insumos para abastecer o rápido crescimento chinês na produção industrial pesada implicou um aumento correspondente no preço desses insumos. Por exemplo, apesar de uma breve queda em resposta à reduzida demanda durante o auge da crise financeira global, o preço do minério de ferro rapidamente recuperou-se na esteira da veloz recuperação da demanda chinesa ${ }^{30}$. Assim, a

para os mercados estrangeiros de exportação. Isso desempenhou um papel fundamental no aumento dos excedentes comerciais chineses com países como os EUA. Ver Anderson (2010, p. 28).

28 Em 2008 o Brasil forneceu 22,7\% das importações chinesas de minério de ferro. Ver Mingramm et alii (2009, p. 12). A mesma dinâmica funcionou para o maior exportador de minério de ferro do mundo: Austrália. Em 2008 a Austrália forneceu 41,4\% das importações chinesas de minério de ferro, e, ao longo da última década, a China tornou-se o maior mercado exportador da Austrália, com minério de ferro e carvão respondendo por um terço do total da receita de exportação australiana. Ver Stutchbury (2010).

29 Apesar de mudanças na estrutura das negociações do preço do minério de ferro, a Vale teve expectativas que sua receita das vendas de minério de ferro para a China dobrasse entre 2009 e 2010. Ver World's Largest Iron (2010). Para uma análise detalhada da estrutura global de comércio entre Brasil e China, ver Dos Santos e Zignago (2010).

30 Para um visão geral do contrato de aumento do minério de ferro e preços “spot”, ver China Ore Import (2009) e Stuart (2010). explosão chinesa na produção industrial pesada teve um papel fundamental na rápida expansão das exportações de uma gama de commodities latino-americanas.

Enquanto a dinâmica entre o aumento da produção de aço chinês e a importação de minério de ferro é um exemplo fundamental da reação em cadeia iniciada pelo veloz crescimento da produção da indústria pesada chinesa, outras commodities minerais latino-americanas também foram puxadas para o distinto padrão de desenvolvimento da China ${ }^{31}$. Por exemplo, boa parte da produção industrial pesada chinesa serviu para abastecer o rápido desenvolvimento de propriedade e infraestrutura. Este, por seu turno, tem impulsionado o aumento das importações de outras commodities minerais latino-americanas como o cobre chileno. Conforme mencionado acima, o cobre é a principal exportação do Chile e a China tem crescido rapidamente para tornarse o maior consumidor do cobre chileno. Assim, o aumento na demanda por um número de recursos minerais abundantes na América Latina, uma ascensão que começou nos primeiros anos do século XXI, tem sido impulsionado por mudanças importantes no padrão de desenvol-

31 A conexão entre minério de ferro e aço fornece a ilustração mais clara de como a demanda chinesa impulsionou as exportações de uma commodity fundamental. $\mathrm{O}$ argumento sustentado aqui encaixa-se melhor em um aumento da produção chinesa de uma série de bens de indústria pesada que necessitam de insumos minerais e energéticos. Entretanto, além dessas “commodities pesadas”, a China experimentou um pico na demanda por commodities agrícolas, ou "commodities leves”, sendo o principal exemplo o dos grãos de soja e de seus derivados, como óleo e farelo (ver a Figura 2). A demanda chinesa por certos insumos agrícolas latinoamericanos, em particular por grãos de soja e óleo de soja, também vinculou-se às mudanças na estrutura no mercado interno chinês. A lógica por trás do aumento na demanda por certas commodities agrícolas, como a soja da Argentina e do Brasil, é diferente daquela por trás dos minerais, mas é discutivelmente também o resultado de mudanças específicas na economia política doméstica da China. Em particular, existe um esforço concertado por parte do governo chinês para sair da suinocultura tamanho-família para uma maior, de aspecto comercial, que impulsionou a maior demanda por importação de soja. Além disso, o aumento da produção industrial tem cada vez mais se traduzido em menos terras para a produção agrícola. Eu agradeço Mindi Schneider e Emelie Paine pelas idéias úteis acerca da conexão Brasil-China da soja. 
vimento doméstico chinês de indústria pesada intensiva ${ }^{32}$.

\section{POR QUE A CHINA VOLTOU-SE PARA A PRODUÇÃO INDUSTRIAL PESADA?}

Se as mudanças na trajetória de desenvolvimento doméstico chinês alimentaram a decolagem de importações de commodities minerais latino-americanas no surto das relações comerciais entre China e América Latina, então avaliar a estabilidade global desse crescente relacionamento comercial depende, em um primeiro momento, de uma compreensão mais profunda do que levou a China a mudar seus padrões de crescimento. Reafirmando uma observação feita acima: da perspectiva de muitos pesquisadores e autoridades, de dentro e fora da China, a volta do país para a produção industrial pesada no começo dos anos 2000 não era planejada nem esperada, produzindo uma série de efeitos indesejáveis. Isso tem importantes implicações para o futuro do desenvolvimento das exportações de commodities para a China, a partir da América Latina ou de outro lugar. Na verdade, muitas das forças que juntas levaram a China ao uso intensivo de capital e energia, seguindo padrões industriais pesados de desenvolvimento, somente foram agravados pela resposta chinesa à crise financeira global. Como as autoridades chinesas moveram-se além do que eles alegaram serem medidas de emergência para proteger a economia chinesa da crise, a atenção dentro e fora da China tem

\footnotetext{
32 Até agora ausente dessa discussão está o aumento do comércio e do investimento chineses em recursos energéticos latino-americanos, especialmente o petróleo. Além dos minerais, as principais atividades de investimento da China na América Latina têm sido vinculadoas aos recursos petrolíferos, incluindo a compra, acima de US\$ 7 bilhões, das operações espanholas da Repsol Brazil, em 2010. Ver Graham (2010). Como este artigo deixa claro, a demanda chinesa por inúmeros produtos de indústria pesada como aço demonstra realçado potencial para a volatilidade relacionada ao mercado e/ou à política. A demanda chinesa em expansão por recursos energéticos, como petróleo ou carvão de coque para a produção de aço, também alimenta preocupações ambientais e outras preocupações de "segurança energética”. Ver Daojiong (2006). Os esforços do governo central chinês para distanciar-se de tamanha dependência no uso de energia intensiva em combustível fóssil claramente terá impacto sobre o footprint da demanda energética chinesa de seus principais parceiros comerciais quanto à exportação de petróleo.
}

crescentemente se focado em como o desequilíbrio de ativos globais e domésticos e as bolhas de capacidade podem ser resolvidas. E como a América Latina e outros exportadores mundiais de commodities têm-se tornado profundamente ligados ao surto, liderado pelos chineses, dessas mercadorias, qualquer mudança na estrutura política e no mercado interno da China também afetará, inevitavelmente, esses exportadores.

Por que nos primeiros anos do século XXI a China afasta-se de um padrão de desenvolvimento baseado em trabalho intensivo (indústria leve) para um baseado na indústria pesada de capital intensivo? Uma resposta para essa questão deve começar com o reconhecimento de que a transição para o desenvolvimento da indústria pesada não foi parte de um plano ou política coordenada por parte do governo central chinês. Como análises econômicas sobre o aumento inesperado do consumo de energia chinês que acompanham a mudança para a indústria pesada deixaram claro, a mudança da estrutura produtiva industrial não foi "o resultado de aspirações nacionais concertadas (como era no tempo de Mao Zedong)" (ROSEN \& HOUSER, 2007, p. 8). Em vez disso, uma combinação perfeita de fatores do mercado e da política governamental levou a um aumento dramático na produção industrial pesada nacional. O que começou como uma série de políticas discretas e sinais do mercado levaram a uma "corrida do ouro" ou uma mentalidade de "surto" de mentalidade (idem; EUROPEAN CHAMBER OF COMMER-CE, 2009). Explicando como a China "struck steel" em uma maneira similar a como outros países "striking oil”, um economista destacou um claro elemento de "exuberância irracional" com o que "começou com uma resposta aos fundamentos do mercado [...] então radicalmente superados" (ANDERSON, 2009, p. 28). O que foram, então, alguns desses fundamentos do mercado?

Uma combinação de condições e políticas macro e microeconômicas facilitaram o surto de produção industrial pesada no começo dos anos 2000. No nível macroeconômico, taxas de poupança cada vez mais elevadas, que aumentaram depois de 2003 até alcançarem quase 52\% do PIB em 2009 (idem, p. 25), combinadas com baixas taxas de juros, para criar capital abundante e barato, alimentaram o surto da produção industrial pesada. Além disso, esses 
aumentos da poupança não têm sido impulsionados pelas famílias, mas pelo aumento da poupança empresarial, a qual subiu, aproximadamente, de 15\% para 26\% do PIB entre 2000 e 2007 (idem, p. 27). Isso significa que o aumento das poupanças empresariais, muitas das quais são empresas estatais, tem sido canalizado para mais investimentos. No nível microeconômico, as possibilidades crescentes de lucros da indústria pesada foram reforçadas por políticas governamentais locais destinadas a aumentar as taxas de crescimento local e atrair investimentos. Por exemplo, como parte da competição para promover o crescimento, governos locais têm frequentemente oferecido insumos subsidiados, incluindo terra, água e eletricidade, para uso industrial (EUROPEAN CHAMBER OF COMMERCE, 2009, p. 14). Ilustrando o impacto dessas políticas nas margens de lucro da indústria pesada, no final dos anos 1990 os lucros desse tipo de indústria pairaram perto de zero, mas em 2007 subiram entre $4 \%$ e $7 \%$ em indústrias como as de aço, vidro e cimento, superando muito as homólogas manufaturas leves (ROSEN \& HOUSER, 2007, p. 10, 12).

Em indústrias pesadas como a do ferro, autoridades do governo central chinês têm-se preocupado com o investimento excessivo há muito tempo, bem como com a falta de concentração industrial (YAP, 2009). No entanto, tal supercapacidade doméstica tem sido estimulada e absorvida por oportunidades para a exportação. Além de subsídios à exportação de determinados produtos industriais pesados, a exportação de excessos da capacidade industrial pesada tem sido auxiliada pelas políticas cambiais do governo central. Mantendo o valor do Yuan baixo, a China tem efetivamente permitido a seus produtores aumentarem a participação no mercado global em determinados setores econômicos (ANDERSON, 2009) ${ }^{33}$. Entretanto, se as exportações da indústria pesada causaram pouco atrito com os parceiros

\footnotetext{
33 Aqui há uma questão legítima sobre se tais resultados podem, de fato, ser um produto de uma política orquestrada para capturar tal participação no mercado. Entretanto, dadas as várias preocupações sobre o excesso de capacidade e os crescentes atritos comerciais gerados por isso, ainda faz sentido ver o que Anderson chama de "ganho de fatia de mercado" como um resultado de um surto não intencional na produção industrial pesada.
}

comerciais antes da crise financeira, elas claramente tem-se tornado uma grande preocupação. Em muitos aspectos o investimento estatal chinês, seja por meio de canais de investimento diretos ou indiretos, tem se traduzido em um aumento da produção industrial pesada, tendo como resultado final uma "corrida do ouro na indústria pesada” (ROSEN \& HOUSER, 2007, p. 12).

\section{EFEITOS DA RESPOSTA CHINESA À CRISE FINANCEIRA: EXCESSO DE CAPACIDADE E AUMENTO DE INSTA- BILIDADE}

Se as condições para essa corrida do ouro na produção industrial pesada, e as condições para a necessidade de matérias-primas, estavam postas antes da crise financeira global, elas somente têm sido exacerbadas pela resposta chinesa à crise. Particularmente, o crédito tornou-se ainda mais barato e mais abundante como resultado do pacote de estímulo chinês de quatro trilhões de Yuan, acompanhado das políticas expansionistas de crédito promovidas por autoridades locais e centrais na esteira da crise financeira ${ }^{34}$. O resultado foi uma rápida recuperação na taxa de crescimento da China, que inspirou alguns a elogiarem o pacote de estímulo chinês como o "padrão ouro" global. Entretanto, o pacote de estímulo e a frouxa política monetária chinesa têm levado a uma preocupação generalizada sobre a formação de bolhas de capacidade (em indústrias pesadas como o aço e o cimento) e de ativos (nos mercados de ações e imobiliário) ${ }^{35}$. Além disso, há um consenso geral dentro e fora da China de que, a fim de ajudar a solucionar os desequilíbrios domésticos e internacionais, a China deve afastarse de sua dependência da demanda externa e avançar em direção a um padrão de crescimento baseado no consumo ${ }^{36}$. Na realidade, porém, a resposta chinesa à crise financeira tem feito pouco

34 Para uma visão abrangente do pacote de estímulo da China e o acompanhamento das políticas de crédito e investimento, ver Naughton (2009b).

35 Para mais detalhes, ver European Chamber of Commerce (2009) e Pettis (2009).

36 Li Keqiang, o provável futuro Primeiro Ministro chinês, tem reiterado a necessidade de tais transformações fundamentais do modelo de desenvolvimento econômico do país. Ver Keqiang (2010). 
para corrigir esses desequilíbrios e, em vez disso, tem estimulado ainda mais o investimento excessivo na indústria pesada e em outras manufaturas que dependem das exportações e, portanto, da demanda externa.

Mais uma vez, o setor siderúrgico fornece um exemplo perfeito de preocupações com a capacidade excessiva, assim como dá sinais de que o setor já pode estar submetido a um realinhamento dirigido pelo Estado, o qual está afetando a demanda por minério de ferro. Enquanto no resto do mundo a produção de aço decresceu aproximadamente 21\% em 2009, a chinesa aumentou 13,5\% (BURNS, 2010). Além disso, das 700 milhões de toneladas de aço produzidas na China em 2009, somente 560 milhões foram consumidas internamente (CHINA MINING ASSOCIATION, 2010). Na primeira parte de 2010, com a economia chinesa respondendo rapidamente ao pacote de estímulo e à inundação de crédito barato, a produção de aço e a exportação continuaram a crescer a taxas de mais de $200 \%$ comparadas com o ano anterior (YAP \& ZHANG, 2010). Com o excesso de capacidade dependente da diminuição da demanda externa dos países mais industrializados da América do Norte e da Europa, as tensões comerciais têm sido rápidas de acompanhar. De fato, "entre os numerosos produtos feitos na China influenciados por atritos no comércio internacional, a indústria siderúrgica chinesa tem sido a mais atingida" (THE CHINA SOURCING, 2010). A supercapacidade não tem sido apenas uma fonte de preocupações comerciais, mas é cada vez mais uma preocupação para os planejadores do governo chinês, que desejam reduzir o consumo doméstico excessivo de fontes de energia que tem acompanhado o aumento da produção industrial pesada (CHINA MINING ASSOCIATION, 2010).

O resultado foi que em 2010 as autoridades do governo central chinês começaram a decretar medidas para reduzir a produção interna de aço e diminuir os incentivos para exportar o excesso de capacidade. Essas medidas começaram a tomar forma em meados de 2010, com a China revogando uma redução de $9 \%$ da taxa sobre o valor agregado para as exportações de aço e, posteriormente, procurando restringir o crescimento do crédito como parte de um esforço maior para desacelerar o mercado imobiliário superaquecido, que é a principal fonte de demanda de grande parte do consumo de aço interno (cf. YAP \& CAMPBELL, 2010; YAP \& ZHANG, 2010). Na década de 1990, as autoridades do governo central preocuparam-se com a falta de consolidação da indústria de aço chinês e declararam suas intenções de interromper a capacidade excessiva e concentrar a produção em um número limitado de grandes empresas estatais de aço (NAUGHTON, 2009a, p. 3-4). Apesar dos profundos desafios na implementação efetiva dessa agenda, esforços iniciados em 2010 para controlar o setor siderúrgico estão começando a engrenar, em parte por causa de preocupações elevadas sobre os efeitos do excesso de aço e de outra capacidade industrial pesada nas relações comerciais, assim como o uso de energia doméstico chinês, para não mencionar a ansiedade sobre o superaquecimento do mercado imobiliário do país. Os esforços da China para controlar a produção de aço e para resfriar o mercado imobiliário superaquecido conduziram a uma montanha russa em 2010 para importações, preços e transporte de minérios de ferro do Brasil e de outros fornecedores-chave na América Latina e em outros lugares (YAP \& CAMPBELL, 2010).

\section{CONCLUSÕES}

No final das contas, as relações entre China e América Latina são mais bem compreendidas como complementares ou dependentes? Essas perspectivas claramente representam dois lados da mesma moeda, capturando uma tensão básica entre o otimismo e a ansiedade que a rápida expansão das relações econômicas entre China e América Latina gerou. Embutidos nesse cenário, entretanto, estão suposições mais complexas sobre os benefícios relativos e a sustentabilidade da recente florescida relação comercial e de investimento China-América Latina. A complementaridade implica equilíbrio e estabilidade: a América Latina, com abundância de recursos naturais, continuará a fornecer a matéria-prima necessária para abastecer a trajetória de desenvolvimento chinesa, que parece inevitavelmente ascendente. A dependência implica um senso de desigualdade e uma falta de sustentabilidade: a América Latina está caindo em velhos hábitos de dependência excessiva de exportação de produtos primários enquanto a China move-se para a progressão do desenvolvimento industrial e manufatureiro. No entanto, este artigo demonstra que as questões sobre a saúde e a sustentabilidade dos laços econômicos entre China e América 
Latina somente podem ser respondidas prestando atenção mais cuidadosa às particularidades do surto de commodities liderado pela China.

Avaliações sobre a saúde e a sustentabilidade dos laços econômicos China-América Latina requerem uma nova ênfase em alguns conhecidos bem fatos, assim como o destaque de alguns fenômenos bem menos discutidos, mas igualmente importantes. Primeiramente, a decolagem dos laços econômicos entre China e América Latina tem sido impulsionada pela demanda chinesa por commodities latino-americanas. Exportações latino-americanas para a China, e o crescente investimento chinês na América Latina, têm sido dominadas pela demanda chinesa por minerais, energia e commodities agrícolas latino-americanas. Em segundo lugar, o momento específico da decolagem de importações chinesas das (e investimento nas) matérias-primas da América Latina é de crucial importância. A América Latina não tem sido simplesmente esboçada nos ventos do milagre econômico chinês dos últimos 30 anos ou mais, mas, em vez disso, tem pegado uma fase específica do ciclo de desenvolvimento chinês, que em aspectos fundamentais tem sido bastante diferente do que veio anteriormente. A crescente demanda por commodities latinoamericanas e de outros países ricos em recursos tem correspondido a uma mudança na trajetória de desenvolvimento doméstico chinês, afastandose da manufatura leve e média baseada em trabalho intensivo e aproximando-se da (super)produção industrial pesada com capital intensivo.

Com esses dois fatos básicos em mente é mais fácil acender uma luz sobre o elefante na sala: o que acontece se e quando o surto de commodities dirigido pela China terminar ou tornar-se propenso a maior volatilidade? Naturalmente, a perspectiva de complementaridade nos leva para longe, mesmo para contemplar esta questão, já que ela não somente assume a continuação suave do rápido desenvolvimento ascendente chinês, como também assume a continuação do papel latinoamericano como um fornecedor de matériasprimas necessárias para abastecer esse desenvolvimento. E aqueles que reconhecem que a América Latina pode estar vinculada a uma fase específica do crescimento chinês (a idéia de que o surto de commodities da China é simplesmente parte de um "superciclo de commodities" secular e virtuoso) distraem-se de qualquer preocupação sobre como o surto pode acabar ${ }^{37}$.
Mais surpreendente, entretanto, é como, freqüentemente, mesmo aqueles que são sensíveis a uma perspectiva mais crítica de dependência estão dispostos a assumir o fim do surto de commodities como uma possibilidade remota. Como um estudo recente nota, "debates sobre o desenvolvimento na América do Sul têm, por cerca de meio século, girado precisamente em torno do imperativo de quebrar a dependência regional em exportações de matérias-primas, especialmente tendo em conta os efeitos deslocados da doença holandesa e outros problemas estruturais associados com tal modelo. A celebração das oportunidades de exportação fornecida pela emergência chinesa tem, conseqüentemente, algo de estranho nela” (PHILLIPS, N., 2010, p. 188-189).

Os relatórios da Cepal e do Banco Mundial discutidos acima são exemplos perfeitos de como aqueles que compreendem melhor do que a maioria essas preocupações históricas estão, todavia, dispostos a pôr de lado a possibilidade de que a demanda chinesa por commodities pode ser propensa à instabilidade. Salientar como os países e empresas latino-americanos exportadores de commodities têm uma oportunidade, bem como uma obrigação, de manejar os ganhos do surto de commodities de uma maneira sustentável, justa e responsável é perfeitamente razoável. Contudo, a falha em melhor entender as raízes da demanda chinesa por commodities específicas e os sérios desafios enfrentados pela China na regulamentação dos mercados responsáveis por tais demandas pode muito bem servir como base para expectativas frustradas quanto à estabilidade chinesa como motor do crescimento da América Latina. Se as expectativas daqueles que estão beneficiando-se mais da complementaridade forem decepcionadas, então haverá também alto potencial para aprofundamento de atritos comerciais com aqueles na América Latina e Caribe que já se encontram competindo cada vez mais com as importações da China. Em última análise, se parciais quanto à perspectiva da dependência ou da complementaridade, muitos do que estão participando ou observando o surto contínuo nas relações China-América Latina parecem ser pegos de surpresa em um ciclo de

37 Para mais sobre os "superciclos" de commodities seculares e a China, ver Rogers (2007; 2008). 
expectativas crescentes que são reflexo mais de uma mentalidade de corrida do ouro do que de uma sóbria reflexão.

Mesmo se tais expectativas crescentes são em parte orientadas pelo que o economista, ganhador do prêmio Nobel, Paul Krugman chamou de "extrapolação ingênua das tendências passadas", este artigo também deixou claro que um enfoque mais cuidadoso na política econômica interna chinesa demonstra os vários desafios enfrentados pela China na manutenção de seu ritmo acelerado de crescimento (KRUGMAN, 1994). Preocupações com os desequilíbrios econômicos internos e externos, com as bolhas de capacidade e ativos, e com a inflação, são apenas algumas das muitas questões no centro das discussões e debates chineses e internacionais sobre a saúde e o futuro da economia chinesa. Esses grandes desafios econômicos estão muito amarrados à demanda chinesa por commodities da América Latina e de outras regiões. Esse argumento também tem aparecido em um número pequeno, mas crescente, de análises de investidores internacionais sobre a economia chinesa. Por exemplo, no final de 2009 e começo de 2010, o investidor de fundos de hedges, James Chanos, ganhou as manchetes com sua observação de que o inflado setor imobiliário chinês parecia "Dubai vezes mil - ou pior” (BARBOZA, 2010) ${ }^{38}$. Chanos, quando mais tarde pressionado a comentar como um estouro da bolha imobiliária chinesa poderia causar impacto na economia mundial, disse que os mais expostos seriam os exportadores de commodities, especialmente nas áreas como as de minério de ferro $^{39}$. Embora os comentários de diretores estrangeiros de fundos de hedge possam ser descartados como especulativos, previsões de uma desaceleração a curto e médio prazo têm

\footnotetext{
38 Chanos foi bem claro ao dizer que ele não previu uma quebra na economia chinesa, mas, em vez disso, que ele estava convencido de que a bolha imobiliária chinesa enfrentaria uma severa correção.

39 Ver a palestra de Chanos (2010) em Oxford, de 28 de janeiro de 2010. Ver também a entrevista de Chanos a Charlie Rose, em 12 de abril de 2010 (ROSE, 2010). Em um exemplo mais recente, Fitch Ratings fez uma simulação do impacto potencial de uma desaceleração simulada do crescimento econômico chinês para menos de 5\% em 2011, a qual destaca o grande impacto negativo nos "setores de energia e commodities" latino-americanos (FITCH RATINGS, 2010, p. 8).
}

crescentemente sido expressas por proeminentes funcionários do governo chinês, bem como do ramo de negócios ${ }^{40}$.

O que permanece, então, é uma incompatibilidade potencialmente volátil entre as altas e crescentes expectativas de um surto de commodities em curso, de um lado, e a possibilidade real de que setores específicos da economia chinesa (por exemplo, a indústria siderúrgica e/ou o mercado imobiliário) enfrentem correções governamentais ou induzidas pelo mercado, as quais terão um impacto sobre a demanda por importações de commodities. O argumento apresentado aqui não é que a economia chinesa enfrenta uma crise iminente, mas simplesmente que certos setores da economia, no centro da demanda chinesa por várias commodities latinoamericanas, enfrentam sérios desafios e são reconhecidos por funcionários do governo central chinês e outros analistas, dentro e fora da China, pela necessidade de reforma e regulamentação. Entretanto, especialmente à luz do elogio que a China recebeu pelo gerenciamento de sua resposta à crise financeira, mantendo altas taxas de crescimento doméstico e, assim, sustentando a demanda por importações da América Latina, a percepção de que a China irá continuar a alimentar o crescimento das exportações latino-americanas continua elevado. Afinal, se a idéia do Consenso de Pequim ou Modelo Chinês ganhou impulso é, em grande parte, porque alguns vêem na China um modelo alternativo e fonte de desenvolvimento.

Contudo, este artigo refutou a noção do senso comum de que, aparentemente, a demanda chinesa por commodities da América Latina é simplesmente decorrência do rápido crescimento da China em longo prazo. A América Latina não é de alguma forma organicamente ligada a uma força desenvolvimentista indestrutível chinesa, mas, em

40 Um exemplo de tais projeções de diminuições nas taxas de crescimento do PIB inclui Lou Jiwei, o chefe do fundo soberano chinês, observando que dentro dos próximos três a quatro anos o crescimento chinês vai diminuir abaixo da tendência dos últimos 30 anos, e nos próximos 20 anos, provavelmente, ficará na média de cerca de 6\%. Ver Sanderson (2010). Para maiores informações sobre as crescentes previsões pessimistas sobre a desaceleração do crescimento econômico chinês no curto ao médio prazo ver Michael Pettis (2010c). 
vez disso, é vinculada a uma fase específica do desenvolvimento chinês que tem cada vez mais apresentado uma série de desequilíbrios, que por sua vez têm suscitado amplas preocupações, das mais variadas, e pedidos de reforma. Os mais conscientes desses desafios são as autoridades chinesas e os estudiosos que estão ativamente trabalhando para a melhor compreensão e resolução desses desequilíbrios. Gerenciar o descompasso entre as expectativas infladas e os sérios desafios envolvidos na sustentação do crescimento econômico estável chinês é responsabilidade tanto de chineses quanto de latino-americanos, bem como de outros observadores interessados. Os líderes chineses devem continuar a tentar trazer estabilidade aos problemáticos mercados internos para as importações de commodities latino-americanas.
Do lado latino-americano, especialmente para aqueles países exportadores de commodities que têm visto a China tornar-se rapidamente o seu principal destino de exportações, é imperativo desenvolver um entendimento com mais nuances da economia política específica da demanda de commodities chinesa. Ambos os lados devem, também, estar conscientes de como a linguagem Sul-Sul e as relações de ganho mútuo alimentam potencialmente expectativas demasiado otimistas de sustentabilidade da demanda de commodities no longo prazo. Gerenciar a atual disparidade entre expectativas elevadas e realidades mais desafiadoras não será fácil, mas certamente será mais fácil do que tentar controlar as conseqüências ao permitir que as bolhas de expectativas estourem.

Matt Ferchen (matt.ferchen@gmail.com) é Doutor em Ciência Política pela Cornell University (EUA) e Professor de Relações Internacionais na Universidade de Tsinghua (China).

\section{REFERÊNCIAS BIBLIOGRÁFICAS}

AGUILAR, G. 2010. Commodity Dependence' Can Lead to Sustained Growth. World Bank Report Argues. The World Bank, Washington (DC), Press Release, n. 2011/083/LAC, 13.Sep. Disponível em: http://web.world bank.org/WBSITE/EXTERNAL/NEWS/ 0 , contentMDK: $22700343 \sim$ page $\mathrm{PK}$ :64257043 piPK:437376 theSitePK: 4607,00.html. Acesso em: 22.set.2011.

ANDERSON, J. 2009. The Myth of Chinese Savings. Far Eastern Economic Review, Hong Kong, v. 172, n. 9, Nov. Disponível em: http:/ /www.allroadsleadto china.com/reports/ Anderson_November.pdf. Acesso em: 20.set.2011.

ANDERSON, S. 2010. Chile's Copper Dependency Has Taken a Turn for the Worse: $55 \%$ of all exports. MercoPress, Montevideo, 16.Nov. Disponível em: http:// en.mercopress.com/2010/11/16/chile-scopper-dependency-has-taken-a-turn-for-theworse-55-of-all-exports. Acesso em: 22.set.2011.

ANDREWS-SPEED, P. 2009. China's Ongoing Energy Efficiency Drive: Origins, Progress and Prospects. Energy Policy, Edinburgh n.
37. Disponível em: http://www.china-sds.org/ kcxfzbg/addinfomanage/rdgz/data/ China\%27s\%20ongoing\%20energy\%2 0efficiency\%20drive\%20Origins,\%20progress\% 20and\%20prospects.pdf. Acesso em: 22.set.2011.

AVENDAÑO, R. \& SANTISO, J. No prelo. Asian Opportunities and Diversification Strategies: An Outlook for Latin American Trade. In: FUNG, K. C.; GARCÍA-HERRERO, G. \& LI-GANG, L. (eds.). China and Latin America: Growing Economic Relations and Commonalities in Policies Issues. $\mathrm{S} / \mathrm{l}: \mathrm{s} / \mathrm{n}$.

BÁRCENA, A.; PRADO, A.; ROSALES, O. \& MALCHIK, S. 2010. Latin America and the Caribbean in the World Economy 2009-2010: A Crisis Generated in the Centre and a Recovery Driven by the Emerging Economies. ECLAC Briefing Paper, n. LC/G. 2467-P, Dec. Disponível em: http://www.eclac.org/cgi-bin/ getprod.asp?xml=/publicaciones/xml/6/40696/ P $40696 . x \mathrm{ml} \& \mathrm{xsl}=/$ comercio/tpl-i/ p9f.xsl\&base=/comercio/tpl-i/top-bottom.xsl. Acesso em: 22.set.2011.

BETHEL, E. 2009. Why Is China Investing Overseas? Seeking Alpha, 26.Aug. Disponível 
em: http://seekingalpha.com/article/158363why-is-china-investing-overseas. Acesso em: 22.set.2011.

BURNS, S. 2010. The Problem with China's Steel Industry. Part One. MetalMiner, 4.Feb. Disponível em: http://agmetalminer.com/2010/ 02/04/the-problem-with-chinas-steel-industry. Acesso em: 22.set.2011.

CALDERÓN, C. 2009. Trade, Specialization and Cycle Synchronizawtion: Explaining Output Comovement Between Latin America, China, and India. In: LEDERMAN, D.; OLARREAGA, M. \& PERRY, G. E. (eds.). China's and India's Challenge to Latin America: Opportunity or Threat? Washington (DC): World Bank.

CHANOS, J. 2010. The China Syndrome: Warning Signs Ahead for the Global Economy. Palestra apresentada em The University of Oxford China Centre, St. Hilda's College, Oxford, 28.jan. Disponível em: http://www.china centre.ox.ac.uk/events/lectures/events/ the_china_syndrome_warning_signs_ahead_ for_the_global_economy. Acesso em: 20.set.2011.

DAOJIONG, Z. 2006. China's Energy Security: Domestic and International Issues. Survival, London, v. 48, n. 1, p. 179-190, Spring. Disponível em: http://docs.china-europaforum.net/doc_209.pdf. Acesso em: 22.set.2011.

DEY-CHAO, W. 2010. Regional Focus: ChinaLatin America. The China Analyst, Beijing, May. Disponível em: http://www.thebeijin gaxis.com/tca/editions/tca-sep-2011/102. Acesso em: 22.set.2011.

DEY-CHAO, W. \& WYK, B. v. 2010. Tatiana Rosito on the State of the China-Brazil Economic Relationship. The China Analyst, Beijing, May. Disponível em: http:// www.thebeijingaxis.com/tca/editions/tcamay-2010/60. Acesso em: 22.set.2011.

DOS SANTOS, E. \& ZIGNAGO, S. 2010. The Impact of the Emergence of China on Brazil International Trade. BBVA, Working Paper, Madrid, n. 10/22, 1.Sep. Disponível em: http:/ /www.bbvaresearch.com/KETD/fbin/mult/ WP_1022_tcm346-231940.pdf?ts=6102010. Acesso em: 22.set.2011.
EGHBAL, M. 2009. Regional Focus: China Strengthens Links with Latin America. Euromonitor International, London, 5.May. Disponível em: http://www.euromonitor.com/ Regional_Focus_China_strengthens_links_ with_Latin_America. Acesso em: 22.set.2011.

ELLIS, E. R. 2008. China in Latin America: The Whats and Wherefores. Boulder: L. Reinner.

ERIKSON, D. P. 2008. The New Challenge: China and the Western Hemisphere. Testimony before the U.S. House Committee on Foreign Affairs, Subcommittee on the Western Hemisphere, Washington (DC), 11.June. Disponível em: http://foreignaffairs.house.gov/ 110/eri061108.htm. Acesso em: 22.set.2011.

FERCHEN, M. No prelo. China, the Idea of Neoliberalism and Illusions of Consensus. Review of International Political Economy, London.

FERCHEN, M. \& GARCÍA-HERRERO, A. 2010. Two Sides of a Coin. China Reform Magazine, Beijing, n. 316, 15.Jan.

FRIEDEN, J. R. 2006. Global Capitalism: Its Fall and Rise in the Twentieth Century. New York: Norton.

GALLAGHER, K. P. \& PORZECANSKI, R. 2009. China and the Latin America Commodities Boom: A Critical Assessment. Political Economy Research Institute, University of Massachusetts Amherst, Working Paper, n. 192. Disponível em: http:/ /www.peri.umass.edu/fileadmin/pdf/ working_papers/working_papers_151-200/ WP192.pdf. Acesso em: 22.set.2011.

GARCÍA-HERRERO, A. \& FUNG, K. C. 2008. China/HK and Latin America: Opportunities and Challenges. BBVA Beijing Conference, Bejing, 3.Dec.

GARNAUT, J. 2010. Hard Choices as China's Boom Fades. The Sydney Morning Herald, Sydney, 13.July. Disponível em: http:// www.smh.com.au/business/hard-choices-aschinas-boom-fades-20100712-107yp.html. Acesso em: 22.set.2011.

GLOSNY, M. A. 2006. Heading Toward a WinWin Future? Recent Developments in China's Policy Toward Southeast Asia. Asian Security, London, v. 2, n. 1, p. 24-57. 
2010. China and the BRICs: A Real (but Limited) Partnership in a Unipolar World. Polity, New York, v. 42, n. 1, p. 100-129. Disponível em: http://www.gwu.edu/ power/ literature/dbase/glosny1.pdf. Acesso em: 22.set.2011.

GRAHAM, M. 2010. China's Growing Investments in Latin America: Will China Replace the U.S. Dominance South of the Border? Spero News, Houston, 9.Nov. Disponível em: http://www.speroforum.com/ a/42959/Chinas-growing-investments-inLatin-America. Acesso em: 22.set.2011.

HALPER, S. 2010. The Beijing Consensus: How China's Authoritarian Model Will Dominate the Twenty-First Century. New York: Basic.

HIRST, M. 2008. A South-South Perspective. In: ROETT, R. \& PAZ, G. (eds.). China's Expansion into the Western Hemisphere: Implications for Latin America and the United States. Washington (DC): Brookings.

KENNEDY, S. 2010. The Myth of the Beijing Consensus. Journal of Contemporary China, London, v. 19, n. 65, p. 461-477. Disponível em: http://chinatrack.typepad.com/files/ kennedy-myth-pub-june-10.pdf. Acesso em: 22.set.2011.

KEQIANG, L. 2010. Shenke lijie “jianyi” zhuti zhuxian cujin jingji shehui quanmian xietiao kechixu fazhan ("Deeply Understand the 'Proposal' to Promote the Comprehensive Coordination of Sustainable Economic and Social Development”). The Central People's Government of the People's Republic of China, 14.Nov. Disponível em: http://www.gov.cn/ ldhd/2010-11/14/content_1745519.htm. Acesso em: 22.set.2011.

KURLANTZICK, J. 2007. Charm Offensive: How China's Soft Power is Transforming the World New Haven: Yale University.

MCKINNON, R. \& SCHNABL, G. 2009. China's Financial Conundrum and Global Imbalances. Bank for International Settlements, Working Paper, n. 277.

MINGRAMM, R. V.; WANG, K.-L.; JIMÉNEZ, A. \& REYES, J. J. 2009. China-Latin America Commodity Trade and Investment: Enduring Trends Towards 2027. SinoLatin Capital, Shanghai, Nov. Disponível em: http:/
/www.sinolatincapital.cn/Upload/ 20091123103159.pdf. Acesso em: 22.set.2011.

NAUGHTON, B. 2008. The Chinese Economy: Transitions and Growth. Cambridge (MA): MIT.

2009a. Loans, Firms, and Steel: Is the State Advancing at the Expense of the Private Sector? China Leadership Monitor, Stanford, n. 30, p. 1-10. Disponível em: http:// media.hoover.org/documents/CLM30BN.pdf. Acesso em: 20.set.2011.

2009b. Understanding the Chinese Stimulus Package. China Leadership Monitor, Stanford, n. 28. Disponível em: http:// media.hoover.org/sites/default/files/documents/ CLM28BN.pdf. Acesso em: 22.set.2011.

2010. China's Distinctive System: Can It $\mathrm{Be}$ a Model for Others? Journal of Contemporary China, London, v. 19, n. 65, p. $437-460$

PALMA, J. G. 1978. Dependency: A Formal Theory of Underdevelopment or a Methodology for the Study of Concrete Situations of Underdevelopment? World Development, Edinburgh, v. 6, n. 7-8, p. 881924.

. 2010. Why Did the Latin American Critical Tradition in the Social Sciences Become Practically Extinct? In: BLYTH, M. (ed.). Routledge Handbook of International Political Economy: IPE as a Global Conversation. London: Routledge.

PETTIS, M. 2009. China September Data: LongTerm Overcapacity Problem is Intensifying. Seeking Alpha, 16.Out. Disponível em: http:/ /seekingalpha.com/article/166966-chinaseptember-data-long-term-overcapacityproblem-is-intensifying. Acesso em: 22.set.2011.

2010a. How Will China Rebalance? Seeking Alpha, 29.Sep. Disponível em: http:/ /seekingalpha.com/article/227660-how-willchina-rebalance. Acesso em: 22.set.2011.

2010b. Never Short a Country with $\$ 2$ Trillion in Reserves. Really? China Financial Markets, 2.Feb. Disponível em: http:// mpettis.com/2010/02/never-short-a-countrywith-2-trillion-in-reserves/. Acesso em: 22.set.2011. 
2010c. QE2 and the Titanic. Seeking Alpha, 10.Nov. Disponível em: http:// seekingalpha.com/article/235993-qe2-and-thetitanic. Acesso em: 22.set.2011.

PHILLIPS, N. 2010. China and Latin America: Development Challenges and Geopolitical Dilemmas. In: DITTMER, L. \& YU, G. T. (eds.). China, the Developing World, and the New Global Dynamic. Boulder: Lynne Rienner.

PHILLIPS, T. 2010. Brazil's Huge New Ports Highlights China's Drive in to South America. The Guardian, London, 15.Sep. Disponível em: http://www.guardian.co.uk/world/2010/sep/15/ brazil-port-china-drive. Acesso em: 22.set.2011.

POMFRET, J. 2010. China Invests Heavily in Brazil, Elsewhere in Pursuit of Political Heft. The Washington Post, Washington (DC), 26.July. Disponível em: http://www.washing tonpost.com/wp-dyn/content/article/2010/07/ 25/AR2010072502979.html?nav=emailpage. Acesso em: 22.set.2011.

RAMO, J. C. 2004. The Beijing Consensus. London: The Foreign Policy Centre.

RATLIFF, W. 2009. In Search of a Balanced Relationship: China, Latin America, and the United States. Asian Politics and Policy, Washington (DC), v. 1, n. 1, p. 1-30.

ROGERS, J. 2007. Hot Commodities: How Anyone Can Invest Profitably in the World's Best Market. New York: Random House.

. 2008. A Bull in China: Investing Profitably in the World's Greatest Market. New York: Random House.

ROSE, C. 2010. Entrevista concedida por James Chanos, 12.abr. Disponível em: http:// www.charlierose.com/view/interview/10960. Acesso em: 22.set.2011.

ROSEN, D. H. \& HOUSER, T. 2007. China Energy: A Guide for the Perplexed. Washington (DC): Peterson Institute for International Economics.

RUPP, S. 2008. Africa and China: Engaging Postcolonial Dependencies. In: ROTBERG, R. I. (ed.). China into Africa: Trade, Aid, and Influence. Washington (DC): Brookings.

SANDERSON, H. 2010. China's Economic Growth May Face 'Big Drop' as Population Ages, CIC Says. Bloomberg, New York,
1.Nov. Disponível em: http://www.bloom berg.com/news/2010-11-01/china-may-facebig-drop-in-growth-within-four-years-cic-slou-jiwei-says.html. Acesso em: 22.set.2011.

SHIXUE, J. 2005. South-South Cooperation in the Age of Globalization: Sino-Latin American Relations. Beijing: Chinese Academy of Social Sciences. Disponível em: http://ilas.cass.cn/ manager/jeditor/UploadFile/200775152 917519.doc. Acesso em: 22.set.2011.

2008. The Chinese Foreign Policy Perspective. In: ROETT, R. \& PAZ, G. (eds.). China's Expansion into the Western Hemisphere: Implications for Latin America and the United States Washington (DC): Brookings.

SINNOTT, E.; NASH, J. \& DE LA TORRE, A. 2010. Natural Resources in Latin America and the Caribbean: Beyond Booms and Busts. Washington (DC): The World Bank.

STUART. 2010. Bullish Comments on Iron Ore Contrary to Recent. MetalMiner, 7.Sep. Disponível em: http://agmetalminer.com/2010/ 09/07/bullish-comments-on-iron-orecontrary-to-recent-trends/comment-page-1/. Acesso em: 20.set.2011.

STUTCHBURY, M. 2010. Exploiting the China boom demands a Big Australin. The Australian, Surry Hills, 5.Aug. Disponível em: http:// www.theaustralian.com.au/business/ exploiting-the-china-boom-demands-a-bigaustralia/story-e6frg8zx-1225901340111. Acesso em: 22.set.2011.

VOLPON, T. 2010. Asia and Latin America: Ready for the Next Step? In: LLEWELLYN, J. \& SANTOVERRI, L. The Ascent of Asia. Tokyo: Nomura Global Economics. Disponível em: http://www.nomuranow.com/research/ globalresearchportal/GetPub.aspx? pid=360239. Acesso em: 22.set.2011.

WYK, B. v. 2010. The China Factor: Supplying China's Phenomenal Demand for Natural Resources. The China Analyst, Beijing, Aug.

YAP, C.-W. 2009. Steel Mills to Government: 'In a Minute'. The Wall Street Journal, New York, 9.Dez. Disponível em: http://blogs.wsj.com/ chinarealtime/2009/12/09/steel-mills-togovernment-\%E2\%80\%98in-a-minute\% E2\%80\%99/. Acesso em: 22.set.2011. 
YAP, C.-W. \& CAMPBELL, J. 2010. As Steel Mills Sneeze, Global Shippers Catch a Cold. The Wall Street Journal, New York, 30.June. Disponível em: http://blogs.wsj.com/chinare altime/2010/06/30/as-steel-mills-sneeze-globalshippers-catch-a-cold/. Acesso em: 22.set.2011.

YAP, C.-W. \& ZHANG, Y. 2010. Government to Steel Mills: 'Your Minute is Up'. The Wall Street Journal, New York, 25.June. Disponível em: http://blogs.wsj.com/chinarealtime/2010/06/ 25/government-to-steel-mills-your-minute-isup/. Acesso em: 22.set.2011.

YONGDING, Y. 2007. Global Imbalances: China's Perspective. Washington (DC): Peterson Institute for International Economics.
2009. China's Policy Responses to the Global Financial Crisis. Melbourne: Australia Government Productivity Comission. Disponível em: http://www.eastasiaforum.org/ wp-content/uploads/2010/01/2009-SnapeLecture.pdf. Acesso em: 22.set.2011.

ZHAO, S. 2010. The China Model: Can it Replace the Western Model of Modernization? Journal of Contemporary China, London, v. 19, n. 65, p. 419-436.

ZWEIG, D. 2010. The Rise of a New 'Trading Nation'. In: DITTMER, L. \& YU, G. T. (eds.). China, the Developing World, and the New Global Dynamic. Boulder: Lynne Reinner.

\section{OUTRAS FONTES}

THE BEIJING AXIS. 2010. The China Analyst, May. Disponível em: http:// www.thebeijingaxis.com/tca/editions/tcamay-2010. Acesso em: 22.set.2011.

\section{CENTER FOR HEMISPHERIC POLICY. 2007.} China Undermines U.S. in Latin America. Latin Business Chronicle, Miami, 4.June. Disponível em: http://www.latinbusinesschronicle.com/ app/article.aspx?id=1297. Acesso em: 22.set.2011.

China Iron Ore Import Price Firm. 2009. China Tells. Disponível em: http://blog.chinatells.com/ 2009/12/3723. Acesso em: 22.set.2011.

CHINA MINING ASSOCIATION. 2010. Problems of China's Steel Industry. Chinamining.org, 13.Apr. Disponível em: http://www.chinamining.org/News/2010-0413/1271126416d35427.html. Acesso em: 22.set.2011.

THE CHINA SOURCING. 2010. The Affect of Trade Sanctions on China's Steel Mills. The China Sourcing, 27.Jan. Disponível em: http:/ /www.chinasourcingblog.org/2010/01/theeffects-of-trade-sanctions.html. Acesso em: 22.set.2011.

EUROPEAN CHAMBER OF COMMERCE. 2009. Overcapacity in China: Causes, Impacts and Recommendations. Beijing: European
Chamber of Commerce in China. Disponível em: http://www.rolandberger.com/media/pdf/ Roland_Berger_Overcapacity_in_China_20091201.pdf. Acesso em: 22.set.2011.

FITCH RATINGS. 2010. The Impact of a China Slowdown on Global Credit Quality, 30.Nov. Disponível em: http://www.oef.com/free/pdfs/ ChinaReport\%20FINAL(30Nov\%2010).pdf. Acesso em: 22.set.2011.

KPMG. 2009. China's Iron and Steel Industry Amid the Financial Crisis. Hong Kong: KPMG. Disponível em: http://www.kpmg.com/CN/en/ Issues AndInsights/ArticlesPublications/ Documents/China-iron-steel-200906.pdf. Acesso em: 22.set.2011.

Latin America Must Take Advantage of Trade with China: ECLAC. 2009. China Daily, New York, 28.Aug. Disponível em: http:// www.chinadai ly.com.cn/bizchina/2009-08/ 28/content_ 8629813.htm. Acesso em: 22.set.2011.

OECD. 2008. China: Encouraging Responsible Business Conduct. OECD Investment Policy. Reviews. Paris: OECD.

World's Largest Iron Ore Producer Cuts Prices by 10\%. 2010. Industry Week, Cleveland, 27.Aug. Disponível em: http://www.industry week.com/articles/worlds_largest_iron_ore_ producer_cuts_prices_by_10_22642.aspx. Acesso em: 22.set.2011. 
RELATIONS BETWEEN CHINA AND LATIN AMERICA: SHORT OR LONG DURATION? Matt Ferchen

This article focuses on business relations and investments involving China and Latin America during the decade of the 2000s. There are three major interpretations, different yet interconnected, on this set of relations. According to the first one, Latin America, a region with abundant natural resources, exports primary products to a China in expansion that is experiencing a shortage of the latter. Close to this interpretation is also another one, advocated by prominent members of government, which asserts that economic relations between China and Latin America are fundamentally complementary and have a positive effect on both. In contrast, other observers have emphasized that what is seen as complementarity is in truth little more than a new form of Latin American dependence. These authors argue that, notwithstanding the rapid expansion of businesses and investments bringing short term benefits to both countries, the nature of these relations based on commodities actually reinforces dysfunctional standards of Latin American development which many countries within the region rejected some time ago and from which they have been trying to free themselves for a period now spanning more than half a century. Taking this discussion as our reference point, we present a general view of trade and investment relations between China and Latin America, highlighting the important role played by Chinese demand for Latin American commodities. This is followed by a description of different interpretations on what guides this commercial relationship as well as what consequences it may produce. We conclude by exploring the implications of our findings with regard to the notion that China provides the sole model for domestic and international political economy.

KEYWORDS: Business; Investment; China, Latin America. 


\section{LES RELATIONS ENTRE LA CHINE ET L’AMÉRIQUE LATINE : DES IMPACTS À COURT OU LONG TERME?}

\section{Matt Ferchen}

L'article met l'accent sur les relations d'affaires et d'investissements entre la Chine et l'Amérique Latine dans les années 2000. Il y a trois interprétations principales, distinguées et liées, sur cet ensemble de relations : pour la première, l’Amérique Latine, une région avec des ressources naturelles abondantes, exporte des produits primaires à une Chine en expansion, mais en manque de ces ressources. En soutenant celle-ci, nous avons ceux, y compris beaucoup de représentants éminents du gouvernement, qui affirment que les relations économiques entre la Chine et l'Amérique Latine sont fondamentalement complémentaires, ayant un effet positif pour toutes les deux. Toutefois, d'autres observateurs soulignent que ce qui est vu comme une complémentarité, n'est en realité qu'une manière renouvelée de dépendance latino-américaine. Ces auteurs disent que, malgré que l'expansion rapide des affaires et investissements apporte des bénéfices à court terme pour les deux côtés, cet espèce de relation basée sur des commodities, renforce les modèles dysfonctionnels de développement de l'Amérique Latine, dont beaucoup de pays de la région ont renoncé il y a déjà longtemps, et essaient d'oublier depuis plus d'un demi-siècle. En prennant cette discussion comme référence, on présente premièrement, une vision générale des relations commerciales et d'investissements entre la Chine et l'Amérique Latine, en soulignant le rôle important de la demande chinoise pour les commodities latino-américaines. Deuxièmement, on décrit les différentes interprétations sur ce qui conduit cette relation commerciale et quelles seraient ses conséquences. Troisièmement, on présente l'argument, soutenu par nous, sur comment nous devrions comprendre ce qui conduit les relations économiques entre la Chine et l'Amérique Latine et ce qui est en jeu. On conclut en vérifiant les implications de nos découvertes avec l’idée selon laquelle, la Chine offre un modèle unique d'économie politique nationale et internationale.

MOTS-CLÉS: les affaires ; les investissements ; la Chine ; l’Amérique Latine. 